\title{
Amelioration of Mitochondrial Dysfunction-Induced Insulin Resistance in Differentiated 3T3-L1 Adipocytes via Inhibition of NF-кB Pathways
}

\section{Mohamad Hafizi Abu Bakar ${ }^{1, *}$, Mohamad Roji Sarmidi ${ }^{2,3, *}$, Cheng Kian Kai ${ }^{1,3}$, Hasniza Zaman Huri ${ }^{4,5}$ and Harisun Yaakob ${ }^{3}$}

1 Department of Bioprocess Engineering, Faculty of Chemical Engineering, University Teknologi Malaysia, Skudai 81310, Malaysia; E-Mail: chengkiankai@cheme.utm.my

2 Institute of Bioproduct Development, University Teknologi Malaysia, Skudai 81310, Malaysia

3 Innovation Centre in Agritechnology for Advanced Bioprocessing (ICA), University Teknologi Malaysia, Skudai 81310, Malaysia; E-Mail: harisun@ibd.utm.my

4 Department of Pharmacy, Faculty of Medicine, University of Malaya, Kuala Lumpur 50603, Malaysia; E-Mail: hasnizazh@ummc.edu.my

5 Clinical Investigation Centre, 13th Floor Main Tower, University Malaya Medical Centre, Kuala Lumpur 59100, Malaysia

* Authors to whom correspondence should be addressed;

E-Mails: mhafizi55@live.utm.my (M.H.A.B.); mroji@ibd.utm.my (M.R.S.);

Tel.: +601-3308-4071 (M.H.A.B.); Fax: +607-5569-706 (M.H.A.B.).

External Editor: Ritva Tikkanen

Received: 13 September 2014; in revised form: 14 November 2014 / Accepted: 15 November 2014 / Published: 2 December 2014

\begin{abstract}
A growing body of evidence suggests that activation of nuclear factor kappa B $(\mathrm{NF}-\mathrm{\kappa B})$ signaling pathways is among the inflammatory mechanism involved in the development of insulin resistance and chronic low-grade inflammation in adipose tissues derived from obese animal and human subjects. Nevertheless, little is known about the roles of NF- $\mathrm{KB}$ pathways in regulating mitochondrial function of the adipose tissues. In the present study, we sought to investigate the direct effects of celastrol (potent NF- $\kappa$ B inhibitor) upon mitochondrial dysfunction-induced insulin resistance in 3T3-L1 adipocytes. Celastrol ameliorates mitochondrial dysfunction by altering mitochondrial fusion and fission in adipocytes. The levels of oxidative DNA damage, protein carbonylation and lipid peroxidation were down-regulated. Further, the morphology and quantification of intracellular
\end{abstract}


lipid droplets revealed the decrease of intracellular lipid accumulation with reduced lipolysis. Moreover, massive production of the pro-inflammatory mediators tumor necrosis factor- $\alpha$ (TNF- $\alpha$ ) and interleukin-1 $\beta$ (IL-1 $\beta$ ) were markedly depleted. Insulin-stimulated glucose uptake activity was restored with the enhancement of insulin signaling pathways. This study signified that the treatments modulated towards knockdown of NF- $\kappa \mathrm{B}$ transcription factor may counteract these metabolic insults exacerbated in our model of synergy between mitochondrial dysfunction and inflammation. These results demonstrate for the first time that NF- $\mathrm{BB}$ inhibition modulates mitochondrial dysfunction induced insulin resistance in 3T3-L1 adipocytes.

Keywords: adipocytes; mitochondrial dysfunction; inflammation; oxidative stress; insulin resistance; celastrol; nuclear factor kappa $\mathrm{B}(\mathrm{NF}-\kappa \mathrm{B})$

\section{Introduction}

In recent years, the roles of mitochondrial dysfunction-induced inflammation towards progression of insulin resistance, the forerunner of type 2 diabetes mellitus, have acquired important new dimensions [1-4]. Indeed, a number of studies have discovered that the impairments of mitochondrial functions in skeletal muscles, liver and adipose tissues of both human and animal disease subjects are etiologically associated with low-grade chronic inflammation [5,6]. In light of data indicating a pathophysiologic role of mitochondrial dysfunction in the occurrence of inflammation and insulin resistance, it is intriguing to hypothesize that the metabolic adaptations observed in these target tissues may affect the whole body metabolism. To a smaller extent, it is now becoming clear that the derangements of cellular inflammatory mediators are inextricably linked to the development of oxidative stress and reduced mitochondrial functions in insulin resistance state. Although the molecular details of such signaling remain enigmatic, several reports have suggested that mitochondrial stress leads to the intense oxidation of mitochondrial DNA, lipid and protein, resulting in the advancement of pro-inflammatory cytokines production in the tissues $[1,5,7]$.

Adipose tissues are the group of heterogeneous mix of adipocytes, which constitute a wide range of fat tissues, immune cells, stroma-vascular cells, such as fibroblast, endothelial cells and pericytes [8]. The integrative roles of these tissues in controlling numerous metabolic signaling pathways are critical for maintaining energy homeostasis. The enlargement adipocytes mass and hyperplasia may lead to reduced oxygen supply with consequent hypoxia. These conditions result in an infiltration of macrophage, resulting in the enormous accumulation of various pro-inflammatory cytokines $[9,10]$. Increasing experimental and clinical evidences have clearly documented that adipose tissue is the most common sites of inflammation in the progression of obesity-related conditions [11,12]. The macrophage infiltration results in the immense production of reactive oxygen species (ROS) and oxidative stress, setting up a vicious cycle and disturbing the steady-state of body homeostatic control [7,13].

Augmented level of circulating cytokines, leukocyte infiltration and oxidative stress have been utilized as the most current model of obesity-linked adipose inflammation [11,14]. An elevation of non-esterified free fatty acid (FFA) level activate inflammatory signaling pathways of toll-like receptor 
(TLR) family and inflammasome through impairment of mitochondrial function in several peripheral tissues [2,15-18]. Overwhelmed production of ROS drives intense oxidation of lipid, proteins and mitochondrial DNA (mtDNA), compromising genes encoding respiratory chain complexes as well as disturbing the efficiency of oxidative phosphorylation as a whole [4,19,20]. In this regard, further experimental analyses should focus on the investigation of inflammatory pathways in modulating mitochondrial functions. The I $\kappa \mathrm{B}$ kinase- $\beta$ (IKK- $\beta$ )/nuclear factor kappa B $(\mathrm{NF}-\kappa \mathrm{B})$ pathway has been implicated in the early key event in the pathogenesis of insulin resistance [6,21]. Presumably through its ability to regulate a wide range of pathological process in insulin resistance, NF- $\kappa$ B dysregulation may directly contributes to variety of metabolic dysfunctions observed in peripheral tissues. Notably, high expressions of inflammatory gene in the context of mitochondrial dysfunctions are vital in enhancing the sensitivity of NF- $\mathrm{BB}$ binding site [22].

Celastrol is a quinone methide triterpenoid that derived from the root of Tripterygium wilfordii (Thunder of God Vine). This active compound possesses several biological activities, including antioxidant, anti-cancer, and anti-inflammatory [23,24]. The exact molecular mechanism for mode of action of this compound is poorly understood with largely unknown functions, but it was shown to act as a potent inhibitor of NF- $\mathrm{kB}$ transcription factors without affecting DNA-binding activity of activator protein 1 (AP-1) [25]. Recently, in vivo co-administration of celastrol in diabetic mice results in the improvement of insulin sensitivity, glycemic control and oxidative stress with significant enhancement of renal functions and structural changes [26]. Nevertheless, there is no current evidence reporting the exact role of celastrol on adipocytes with insulin resistance.

As mitochondrial dysfunction is strongly associated with the development of insulin resistance, we undertook a more focused approach at the cellular level to investigate the systematic roles of IKK- $\beta / \mathrm{NF}-\kappa \mathrm{B}$ pathways inhibition in alleviating mitochondrial dysfunction-induced insulin resistance in 3T3-L1 adipocytes. This study established an in vitro model of insulin resistance induced by oligomycin (ATP synthase inhibitor) on 3T3-L1 adipocytes. In this study, we observed the mechanistic effects of celastrol (NF- $\mathrm{BB}$ inhibitor) on the mitochondrial functions, lipolysis with intracellular lipid accumulation, glucose uptake activity, insulin-signal-transduction related molecules such as insulin receptor substrate 1 (IRS1), Akt/protein kinase B (PKB), Akt substrate of $160 \mathrm{kDa}$ (AS160), glucose transporter 1 (GLUT1) and glucose transporter 4 (GLUT4). The levels of pro-inflammatory cytokines were also measured in the study, with an attempt to investigate that NF- $\mathrm{BB}$ pathway is the target for ameliorating mitochondrial dysfunction in the development of insulin resistance and type 2 diabetes.

\section{Results and Discussion}

\subsection{Effect of Oligomycin and Celastrol on the Cell Viability and NF- $\kappa B$ Expression of 3T3-L1 Adipocytes}

We used differentiated 3T3-L1 adipocytes as an in vitro cellular model to study the ameliorative properties of celastrol on mitochondrial dysfunction induced by mitochondrial inhibitor oligomycin that can lead to insulin resistance. The viability assay was used to determine the suitable concentration and possible cytotoxic effects of oligomycin (Figure 1A) and celastrol (Figure 1B) treatments on fully differentiated 3T3-L1 adipocytes. After serum starvation, 3T3-L1 adipocytes were incubated in the presence of different doses of oligomycin and celastrol for $48 \mathrm{~h}$. As shown in Figure 1C, both oligomycin 
and celastrol decreased the cell viability in a dose-dependent manner. The optimal dose of oligomycin that did not affect the cell viability was $10 \mu \mathrm{M}$. The cell viability of 3T3-L1 adipocytes incubated with celastrol discovered that the significant decline of cell viability was exhibited at the concentration of 10,20 and $30 \mu \mathrm{M}$ by $37 \%, 48 \%$ and $56 \%$, respectively. Accordingly, optimal dose of 10 and $5 \mu \mathrm{M}$ for oligomycin and celastrol were chosen in the assay, respectively. The time-course dependent was evaluated for each optimal dose (Figure 1D). The result depicted that 24 and $48 \mathrm{~h}$ treatment of both inhibitors on 3T3-L1 adipocytes did not significantly reduce the cell viability. Therefore, $48 \mathrm{~h}$ treatment of both inhibitor was chosen. Additionally, to confirm with our hypothesis on the involvement of NF- $\kappa \mathrm{B}$ activation in the event of mitochondrial dysfunction, the protein expression of NF- $\kappa \mathrm{B}$ level in both treated group was measured. The result showed that oligomycin significantly $(p<0.05)$ amplified NF- $\kappa$ B expression by $50 \%$ in the differentiated 3T3-L1 adipocytes whereas $29 \%$ reduction of NF- $\kappa \mathrm{B}$ expression was exhibited by cells incubated with celastrol compared to control cells (Figure 1E).

Figure 1. Effects of oligomycin and celastrol on cell viability. Chemical structures of (A) oligomycin and (B) celastrol were shown; The $(\mathbf{C})$ dose-response and (D) time course of the cell viability for oligomycin and celastrol was determined via MTT assay. After serum starvation, the fully differentiated 3T3-L1 adipocytes were incubated with different doses of oligomycin $(5,10,20$ and $30 \mu \mathrm{g} / \mathrm{mL})$ and celastrol $(5,10,20$ and $30 \mu \mathrm{M})$ in DMSO for $48 \mathrm{~h}$. Time-course dependent $(0,12,24,36$ and $48 \mathrm{~h})$ was determined for each optimal dose. Effect of oligomycin and celastrol on nuclear factor kappa B (NF-kB) expression was performed via (E) immunoblotting analysis. $\beta$-actin was used as loading control. Protein levels measured were normalized against $\beta$-actin. Results were expressed as means \pm SEM $(n=6-8) .{ }^{*} p<0.05 v s$. untreated control.
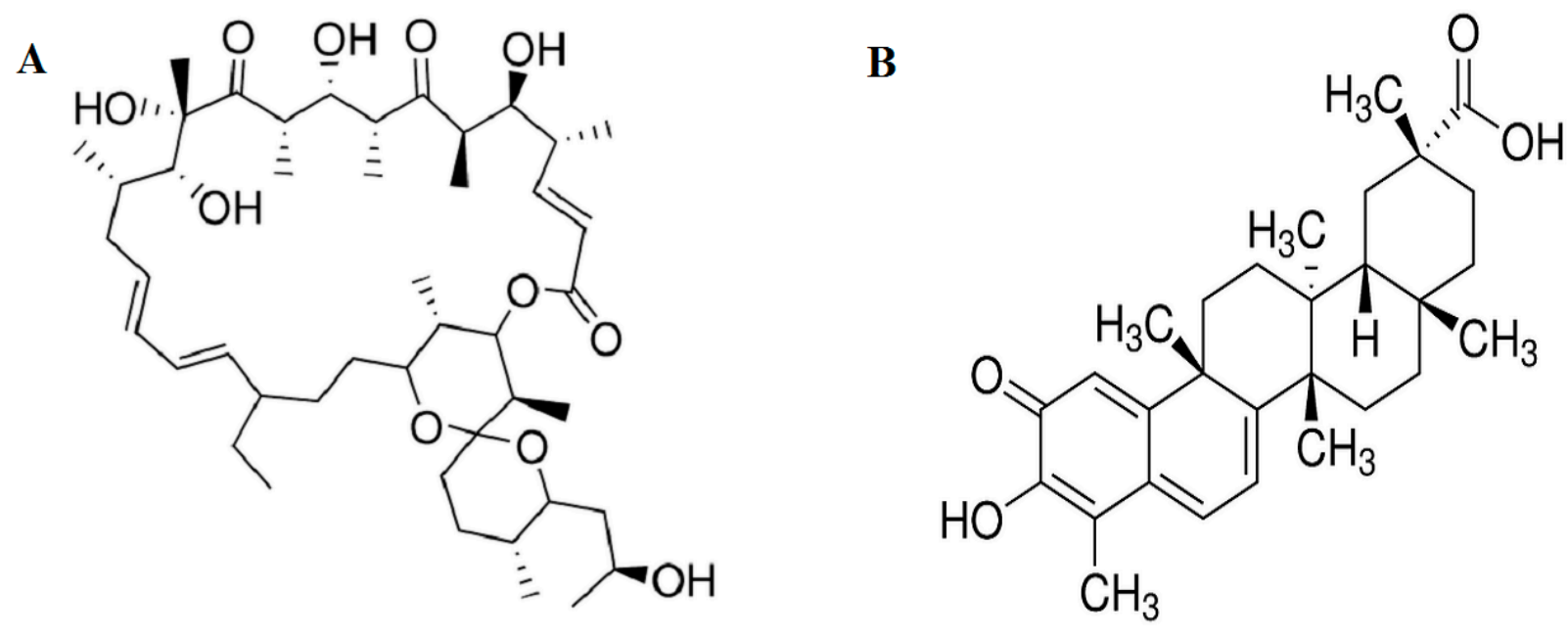
Figure 1. Cont.
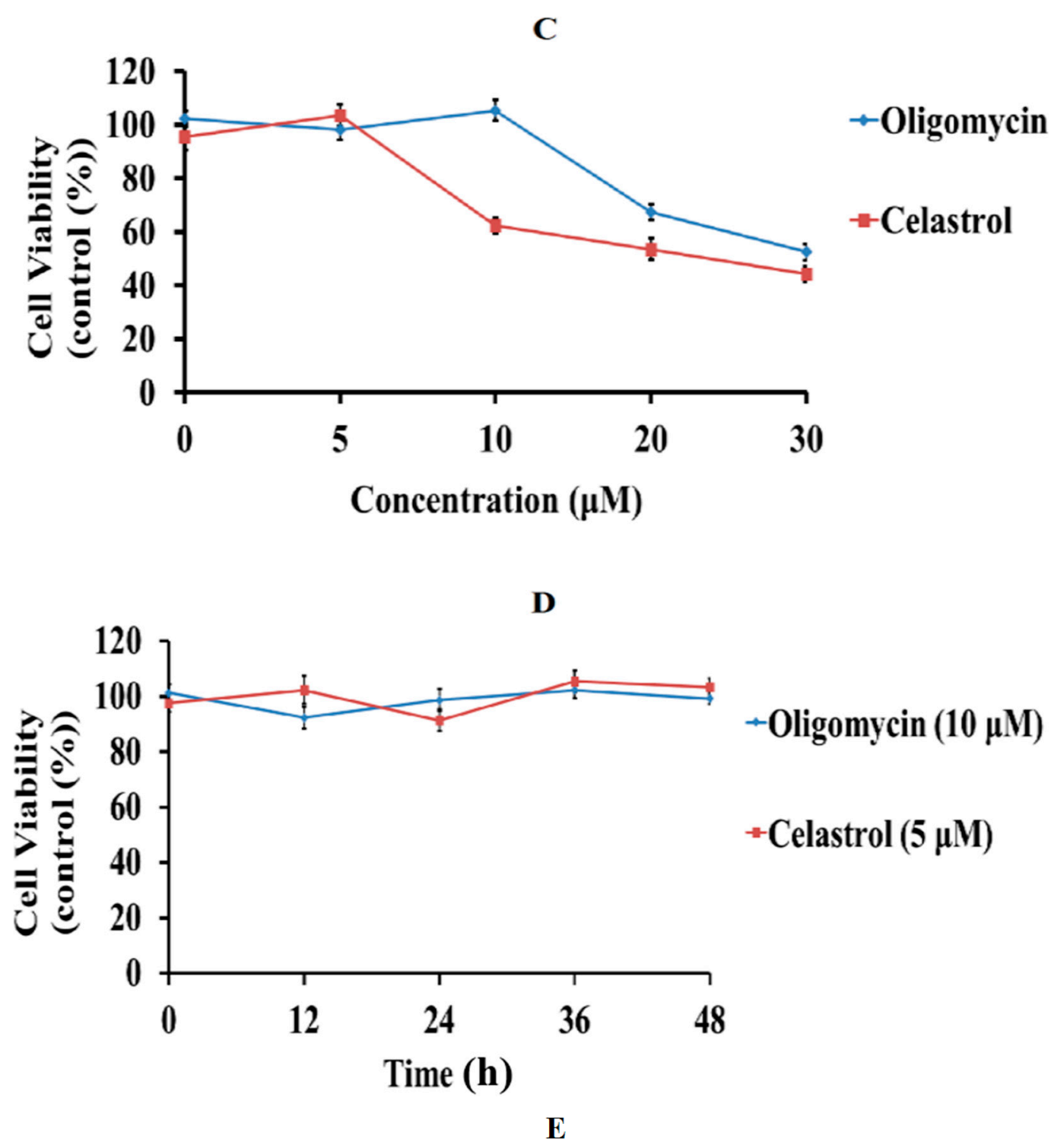

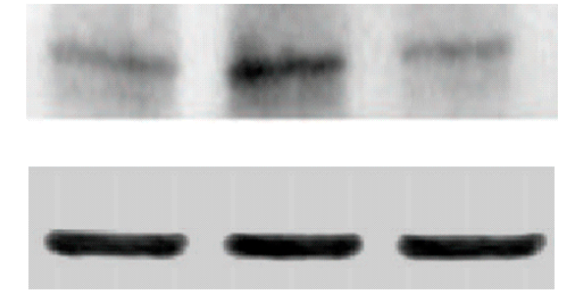

Control Oligomycin Celastrol
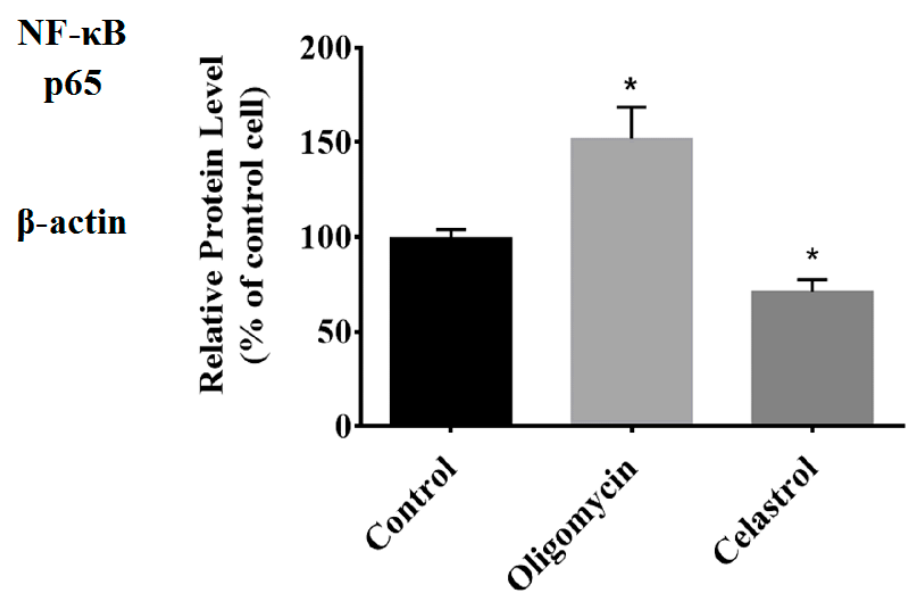


\subsection{NF- $\kappa B$ Inhibitor Recues 3T3-L1 Adipocytes from Oligomycin Induced Mitochondrial Dysfunction}

As shown in Figure 2A, exposure of differentiated 3T3-L1 adipocytes to oligomycin for $48 \mathrm{~h}$ significantly decreased mitochondrial intracellular ATP concentration at the basal $(48 \%, p<0.05)$ and insulin-stimulated condition $(58 \%, p<0.01)$ compared to untreated control. After then, we inhibited the activation of NF- $\kappa \mathrm{B}$ using $5 \mu \mathrm{M}$ celastrol after exposure of 3T3-L1 adipocytes to oligomycin. The result revealed that celastrol significantly attenuated mitochondrial dysfunction in adipocytes treated with oligomycin by enhancing intracellular ATP concentration in the absence $(28 \%, p<0.05)$ and presence of insulin $(41 \%, p<0.05)$ (Figure $2 \mathrm{~A})$. To explore this relationship further, measurement of mitochondrial membrane potential was carried out. The results showed that oligomycin markedly $(70 \%$, $p<0.01)$ lessened the mitochondrial membrane potential of the adipocytes and this reduction was significantly inhibited by an escalation of $61 \%(p<0.05)$ mitochondrial membrane potential after co-administration with celastrol for $48 \mathrm{~h}$ compared to control (Figure 2B). Mitochondrial superoxide production was determined with a fluorescence probe Mitosox ${ }^{\mathrm{TM}}$ Red (Invitrogen Molecular Probes, Carlsbad, CA, USA). Treatment of 3T3-L1 adipocytes with oligomycin significantly resulted in the elevation of ROS production by 50\% $(p<0.05)$ compared to untreated control but was evidently diminished by celastrol treatment as much as $29 \%(p<0.05)$ (Figure $2 \mathrm{C})$.

Figure 2. Effects of celastrol on mitochondrial function of differentiated 3T3-L1 adipocytes with mitochondrial dysfunction was assessed via (A) intracellular ATP concentration; (B) mitochondrial membrane potential (MMP) and (C) mitochondrial superoxide production. Basal level and insulin-stimulated condition are shown. Basal rate refers to the rate of glucose transport in the absence of insulin. Results are expressed as means $\pm \operatorname{SEM}(n=6)$. ${ }^{*} p<0.05$ and $* * p<0.01$ vs. untreated control; ${ }^{*} p<0.05$ vs. basal rate; ${ }^{+} p<0.05$ vs. oligomycin-treated cells.

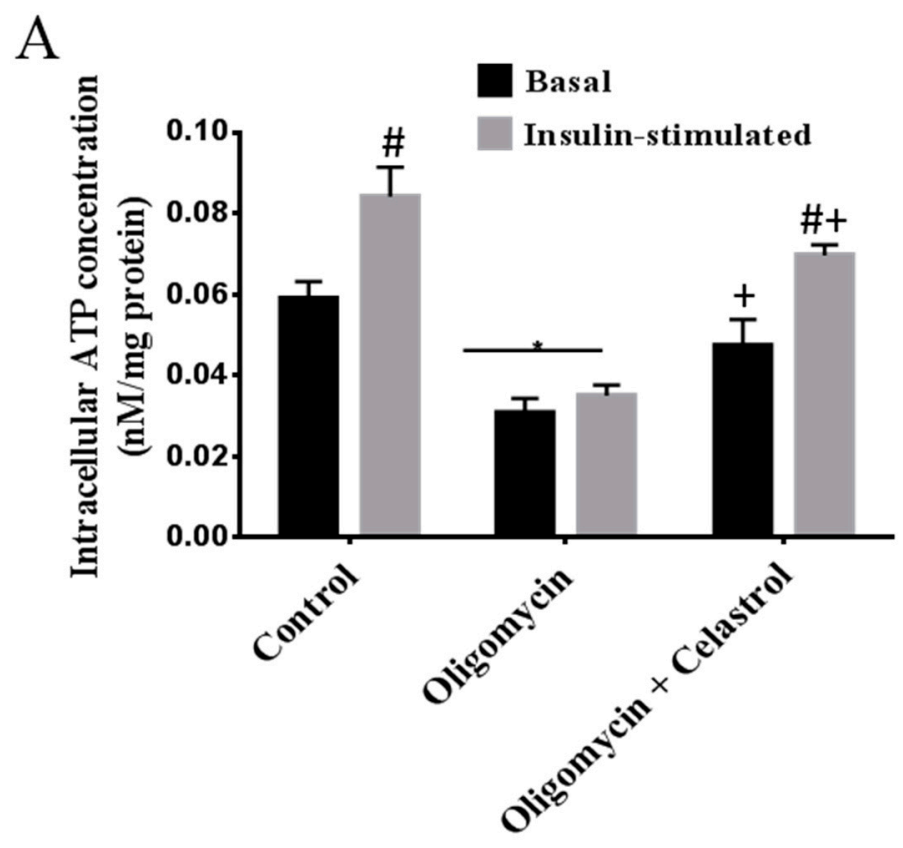


Figure 2. Cont.
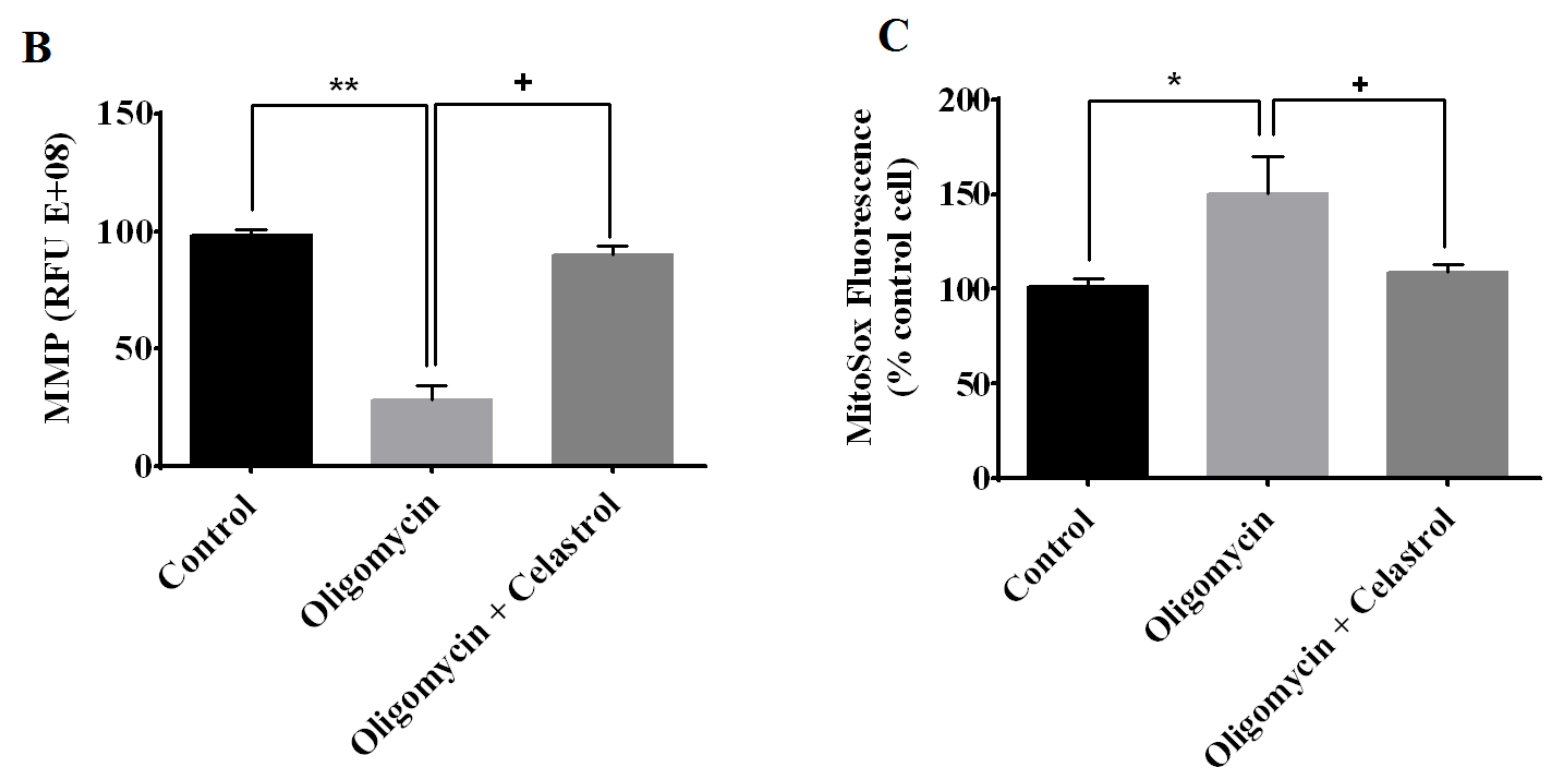

\subsection{Effect of Celastrol on Mitochondrial Dynamics of 3T3-L1 Adipocytes with Mitochondrial Dysfunction}

Mitochondrial dynamics involving fusion and fission have been recognized as one of the key occasions in the mitochondrial metabolism. To study the involvement of NF- $\kappa$ B activation in adipocytes with mitochondrial dysfunction, we continued to examine the mitochondrial protein levels such as mitofusin 1 (Mfn1), mitofusin 2 (Mfn2), and dynamin-related protein 1 (Drp1), which are participated in mitochondrial dynamics process. Our data showed that oligomycin treatment lead to the significant declined of Mfn1 protein level by $40 \%$ in 3T3-L1 adipocyte, but was significantly re-amplified (30\%, $p<0.05$ ) by celastrol (Figure 3A). However, we found no significance difference on Mfn2 protein levels on adipocytes treated with oligomycin as well as co-treatment with celastrol (Figure 3B). Meanwhile, Drp1 protein level was augmented $(38 \%, p<0.05)$ in oligomycin treated cells compared to control cells and completely reversed by celastrol (Figure 3C).

\subsection{Effect of Celastrol on Impairment of Mitochondrial Respiratory Chain Elicited Oxidative Stress in 3T3-L1 Adipocytes}

Oxidative stress is a key link between inflammation and insulin resistance [6]. To address this association, the oxidative profile of adipocytes treated with oligomycin and its co-incubation with NF- $\mathrm{B}$ inhibitor was evaluated. Oligomycin significantly multiplied the formation of 8-hydroxydeoxyguanosine $(8-\mathrm{OHdG})$ by 3.21 -fold $(p<0.01)$ in 3T3-L1 adipocytes. In parallel, our data evidenced that treatment with the celastrol on adipocytes with mitochondrial dysfunction significantly diminished the formation of 8 -OHdG level by 1.87 -fold $(p<0.01$ ) (Figure 4A). The role of protein carbonylation in the pathogenesis of mitochondrial dysfunction and oxidative stress-related inflammation is well recognized [27]. Hence, calorimetric quantification of carbonylation of protein by-products was employed. In this study, we found that carbonylation of proteins was considerably $(p<0.01)$ elevated in oligomycin-treated cells than those of the control. The regulatory effect of celastrol on adipocyte with increased protein carbonylation was then further examined. Evaluation of protein carbonylation assay showed that co-incubation of 
oligomycin-treated adipocytes with celastrol reduced the protein carbonylation levels by 0.8 -fold $(p<0.05)$ compared to oligomycin-treated cells (Figure 4B).

Figure 3. Effects of celastrol on mitochondrial dynamics of differentiated 3T3-L1 adipocytes treated with oligomycin. The mitochondrial fusion/fission protein levels in adipocytes treated with oligomycin, celastrol and control cells were analyzed by Western blot with the corresponding antibodies. Representative Western blot and densitometric analysis of Western blot results for (A) Mfn1, (B) Mfn2, and (C) Drp1 were determined. $\beta$-actin was used as loading control. Protein levels measured by densitometry were normalized against $\beta$-actin signals. The results are similar of those obtained from three independent experiments. ${ }^{*} p<0.05$ vs. untreated control; ${ }^{+} p<0.05$ vs. oligomycin-treated cells; ns: not significant.

A

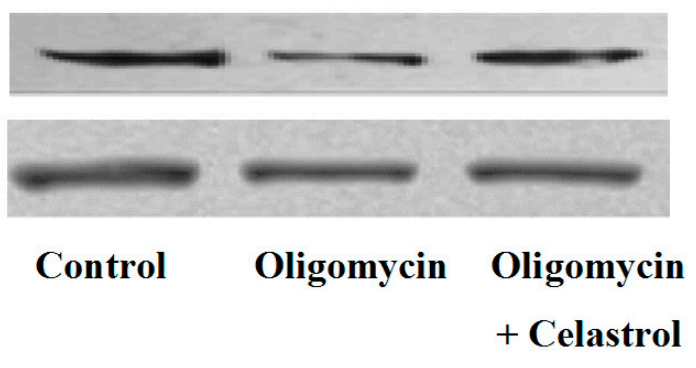

Mfn1

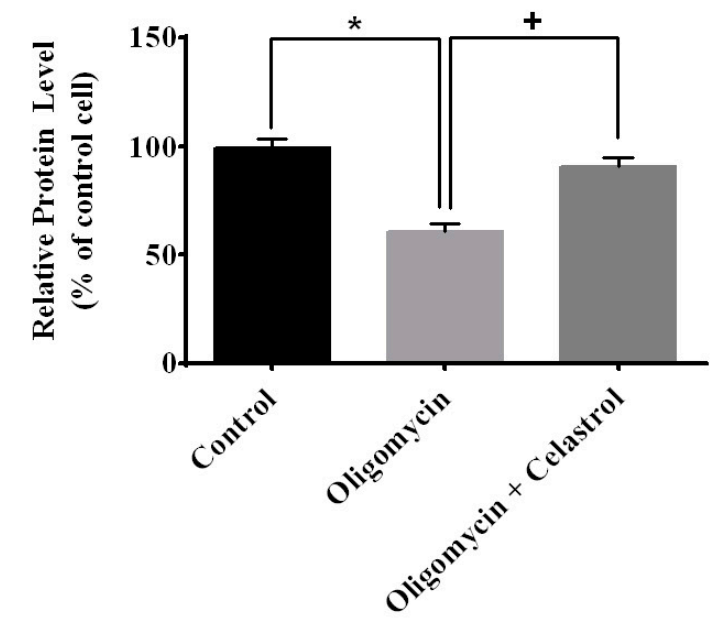

B
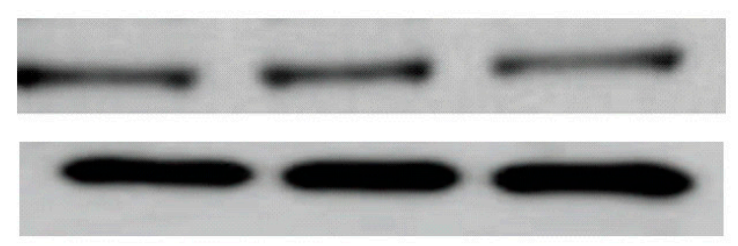

Control

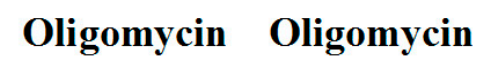

+ Celastrol

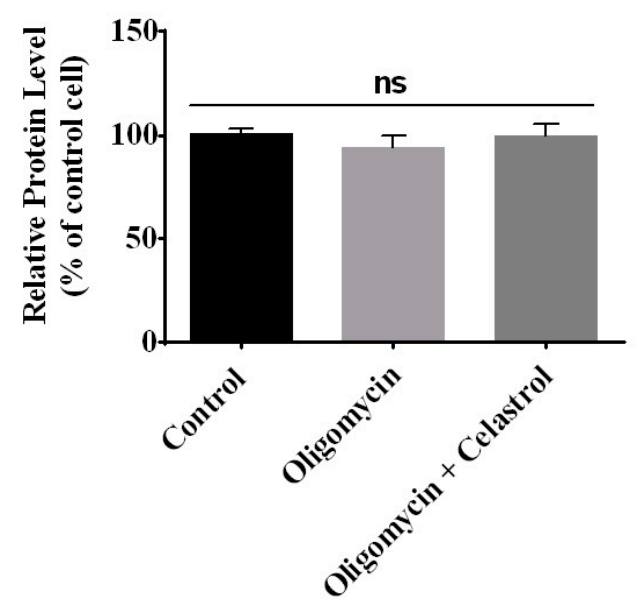


Figure 3. Cont.

C

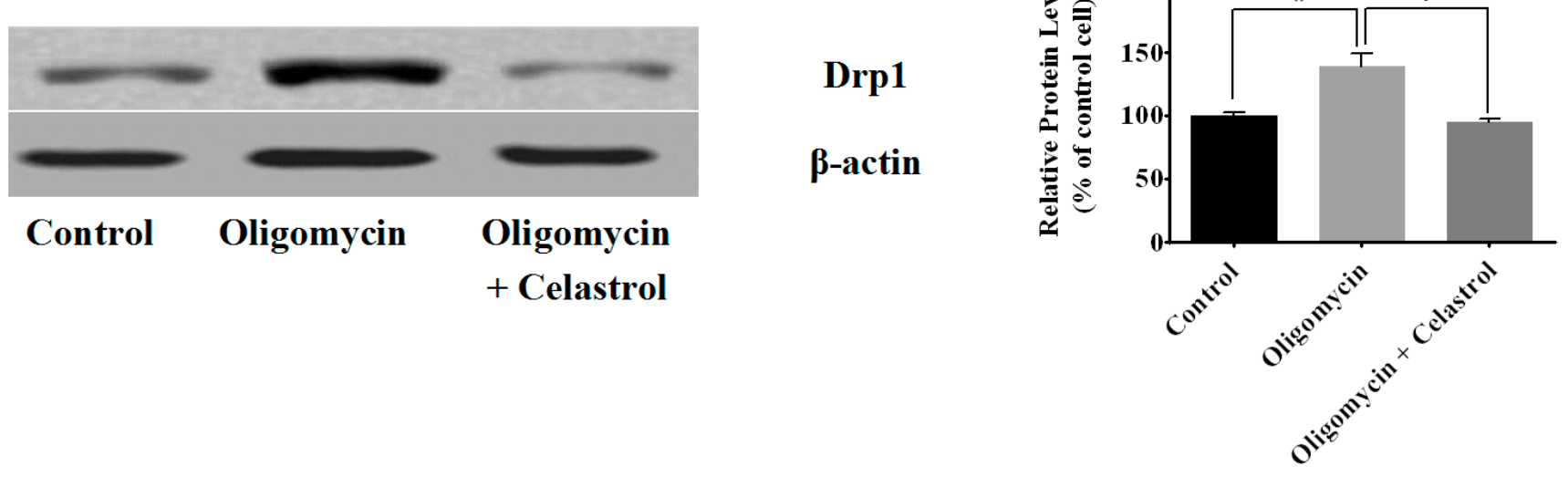

We then measured the lipid peroxidation of adipocytes with mitochondrial dysfunction induced by oligomycin treatment. The result revealed a significant upsurge of the lipid peroxidation (MDA) level in adipocytes treated with oligomycin compared to untreated control $(270 \%, p<0.01)$. In addition to the improvement of DNA oxidative damage and protein carbonylation, co-treatment with celastrol in oligomycin-treated cells exhibited with amelioration of lipid peroxidation level by 1.39 -fold reduction $(p<0.01)$ (Figure 4C), signifying the enhancement of oxidative profile by inhibiting NF- $\kappa \mathrm{B}$ activation may directly contribute to a significant role in rescuing adipocytes from the state of mitochondrial dysfunction induced by oligomycin.

\subsection{NF- $\kappa B$ Inhibitor Reduces Lipolysis and Alleviates Accelerated Intracellular Lpid Accumulation in} 3T3-L1 Adipocytes with Mitochondria Dysfunction

Lipolysis is the key metabolic process via engagement of the triglycerides breakdown into three molecules of free fatty acids and one molecule of glycerol. To determine the effect of NF- $\kappa \mathrm{B}$ inhibitor on lipolysis in the context of mitochondrial dysfunction of adipocytes, the quantification of the free fatty acid and glycerol release was measured. Treatment with oligomycin on 3T3-L1 adipocytes significantly intensified the release of fatty acids and glycerol from adipocytes by $0.7-(p<0.05)$ and 2.36 -fold $(p<0.01)$, respectively, compared to untreated cells. NF- $\kappa \mathrm{B}$ inhibition by celastrol leads to the pronounced reduction in free fatty acids $(64 \%, p<0.05)$ and glycerol $(197 \%, p<0.01)$ release compared to oligomycin-treated cells, signifying the down-regulation of lipolysis in the adipocytes with mitochondrial dysfunction could be modulated towards knockdown of NF- $\kappa$ B activation (Figure 5A,B). 
Figure 4. Effects of celastrol treatment on oligomycin-induced oxidative stress in 3T3-L1 adipocytes. Celastrol significantly reduced the oxidative stress of adipocytes with mitochondrial dysfunction. Oxidative profiles of adipocytes were determined via (A) measurement of DNA oxidative damage (8-OHdG); (B) protein carbonylation and (C) lipid peroxidation (MDA). Results are expressed as means $\pm \operatorname{SEM}(n=6)$. ** $p<0.01 v s$. untreated control; ${ }^{+} p<0.05$ and ${ }^{++} p<0.01 v s$. oligomycin-treated cells.

A
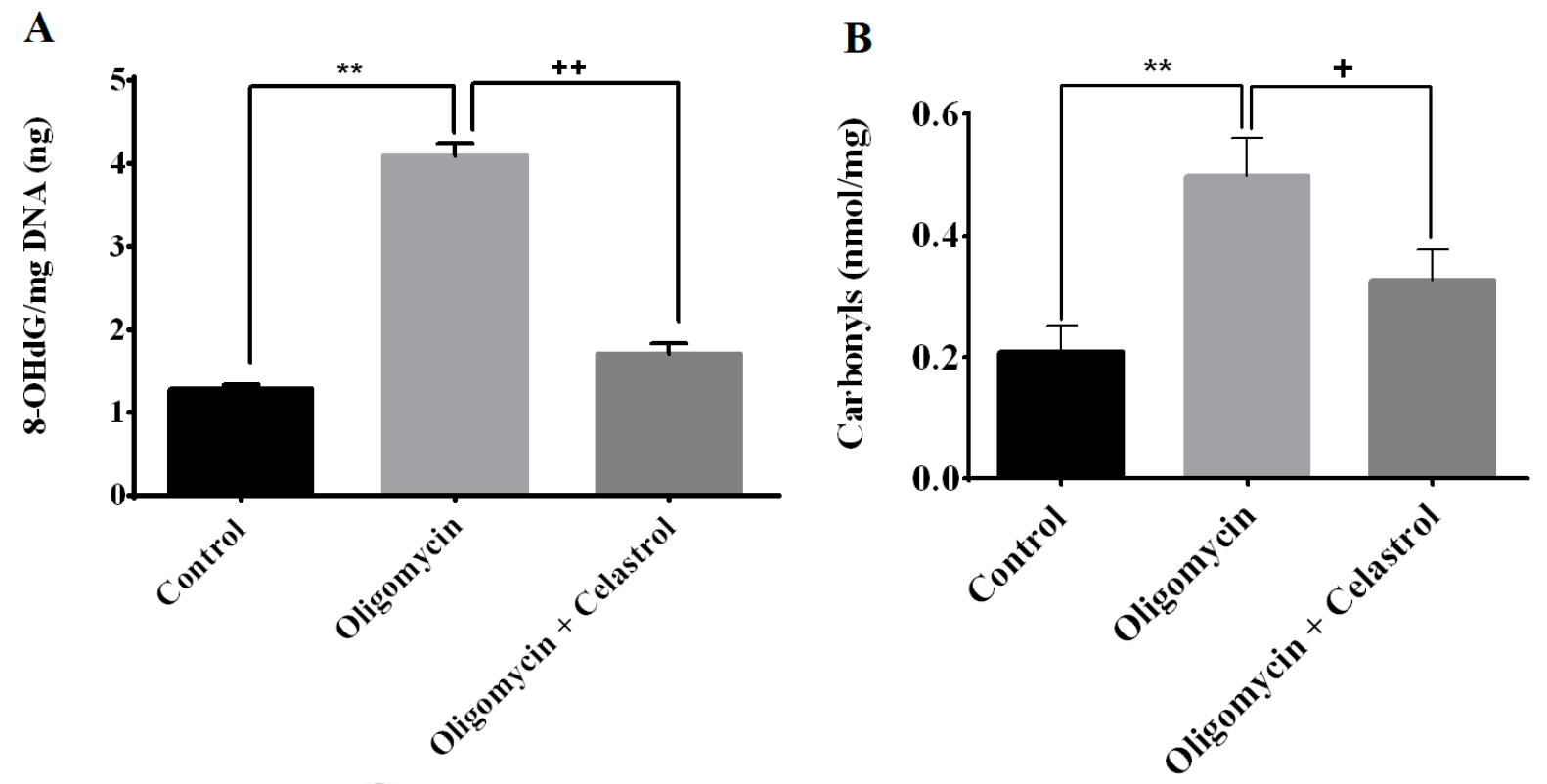

$\mathrm{C}$
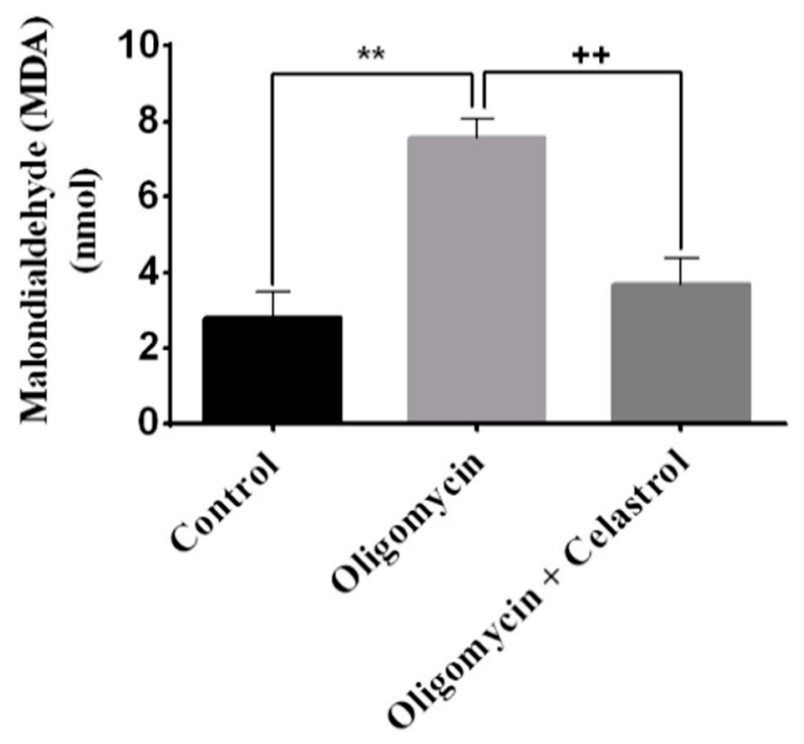

Concomitant to lipolysis, we then focused on intracellular lipid accumulation to determine if celastrol has an effect on intracellular lipid deposition of 3T3-L1 adipocytes. The intracellular lipid accumulation in 3T3-L1 adipocytes treated with oligomycin and celastrol was assessed via Oil Red $\mathrm{O}$ assay (morphological and spectrophotometric quantification). It is worth noting that treatment of 3T3-L1 adipocytes with oligomycin significantly boosted the intracellular lipid accumulation. As visualized using Oil Red O staining, the formation of numerous cytosolic lipid droplets, larger and prominent increase in lipid vesicles with scattered and abnormal lipid droplet distributions were observed in 3T3-L1 adipocytes treated with oligomycin (Figure 5E) compared to the vehicle-treated cells with 
DMSO (Figure 5C) and MDI (3-isobutyl-1-methylxanthine, dexamethasone, and insulin) induction media (Figure 5D). The normal differentiated cells treated with MDI were exhibited with a typical adipocyte phenotype with round-shaped lipid droplets. In the quantitative examination using optical density at $490 \mathrm{~nm}$, the addition of oligomycin in differentiated 3T3-L1 adipocytes was shown to up regulate intracellular lipid accumulation by $67 \%(p<0.05)$ compared with MDI-treated cells (Figure 5G). Importantly, we demonstrated that the metabolic inhibition of NF- $\kappa$ B pathways by celastrol significantly $(p<0.05)$ reduced the intracellular accumulation of lipid droplets in adipocytes with insulin resistance by $52 \%$ as morphologically and quantitatively shown in Figure 5F,G.

Figure 5. Effects of celastrol treatment on lipolysis and intracellular lipid accumulation of differentiated 3T3-L1 adipocytes with mitochondrial dysfunction. In the presence of MDI, fully differentiated 3T3-L1 adipocytes were incubated with oligomycin and celastrol for $48 \mathrm{~h}$ differentiated cells were on analyzed for (A) free fatty acids and (B) glycerol release as described in materials and methods. The Oil Red $\mathrm{O}$ stained adipocytes were photographed at $40 \times$ magnification; (C) Untreated control (DMSO); (D) MDI-treated cells; (E) Oligomycin-treated cells and (F) Oligomycin + celastrol-treated cells. Figures represent one of three independent experiments; and (G) Quantification of intracellular lipid droplets in 3T3-L1 adipocytes treated with oligomycin and celastrol was performed accordingly. The results are representative of those obtained from three independent experiments. All values are presented as means \pm SEM of three independent experiments. ${ }^{*} p<0.05$ and $* * p<0.01 v s$. untreated cells; ${ }^{+} p<0.05$ and ${ }^{++} p<0.01 v s$. oligomycin-treated cells.

A

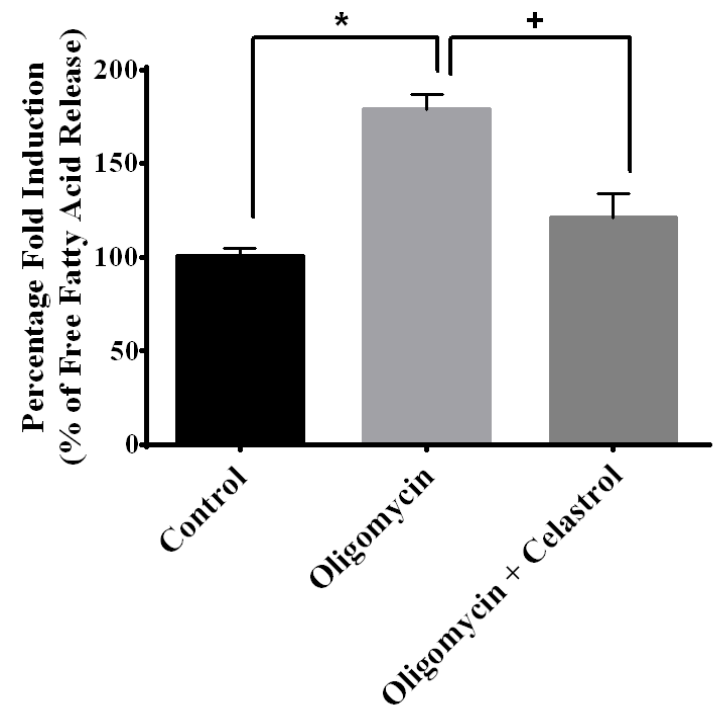

B

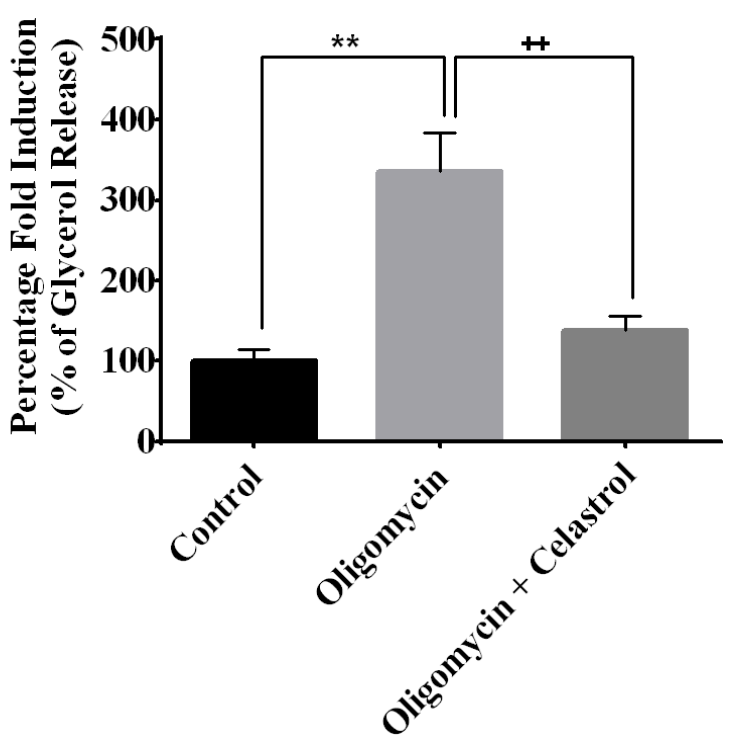


Figure 5. Cont.
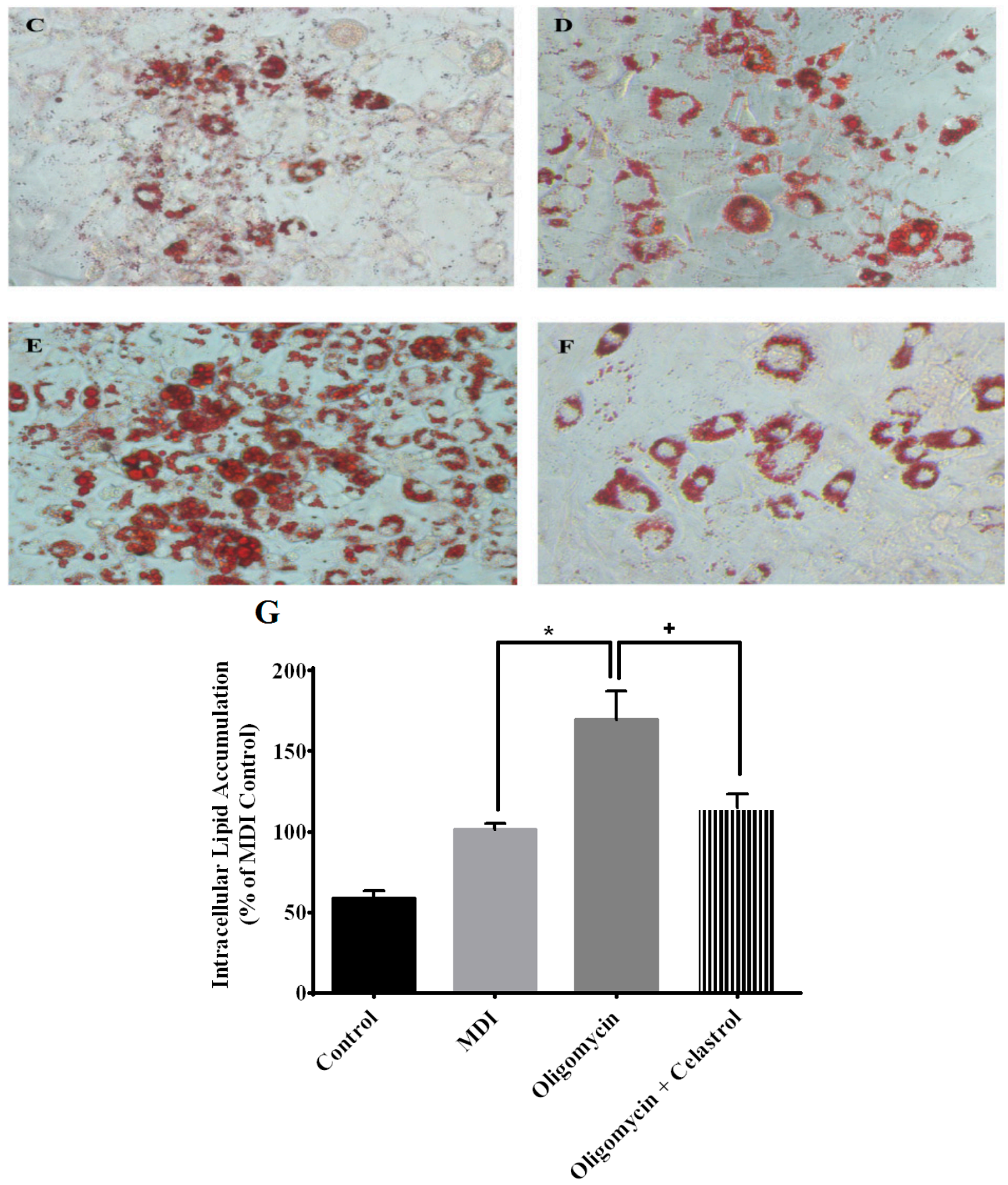

2.6. NF- $\kappa B$ Inhibitor Suppress Production of Tumor Necrosis Factor- $\alpha(T N F-\alpha)$ and Interleukin-1 $\beta$ $(I L-1 \beta)$ in the Event of Mitochondrial Dysfunction of 3T3-L1 Adipocytes

IL-1 $\beta$ and TNF- $\alpha$ are major circulating cytokines that promote inflammatory action in adipocytes. As shown in Figure 6A,B, treatment with oligomycin on fully differentiated 3T3-L1 adipocytes for $48 \mathrm{~h}$ significantly led to the amplification of IL-1 $\beta$ (4.63-fold, $p<0.01)$ and TNF- $\alpha(4.15$-fold, $p<0.01)$ secretion from adipocytes compared to untreated control. Celastrol significantly decreased the release of TNF- $\alpha(2.68$-fold, $p<0.05)$ and IL-1 $\beta$ (3.37-fold, $p<0.05)$ from adipose tissue. 
Figure 6. Effects of celastrol treatment on differentiated 3T3-L1 adipocytes treated with oligomycin. The measurement of pro-inflammatory cytokine (A) interleukin-1 $\beta$ (IL-1 $\beta$ ) and (B) tumor necrosis factor- $\alpha(\mathrm{TNF}-\alpha)$ was analyzed using a commercially available ELISA kit. Results were expressed as means $\pm \operatorname{SEM}(n=8) . * * p<0.01 v s$. untreated control; ${ }^{+} p<0.05$ vs. oligomycin-treated cells.

A

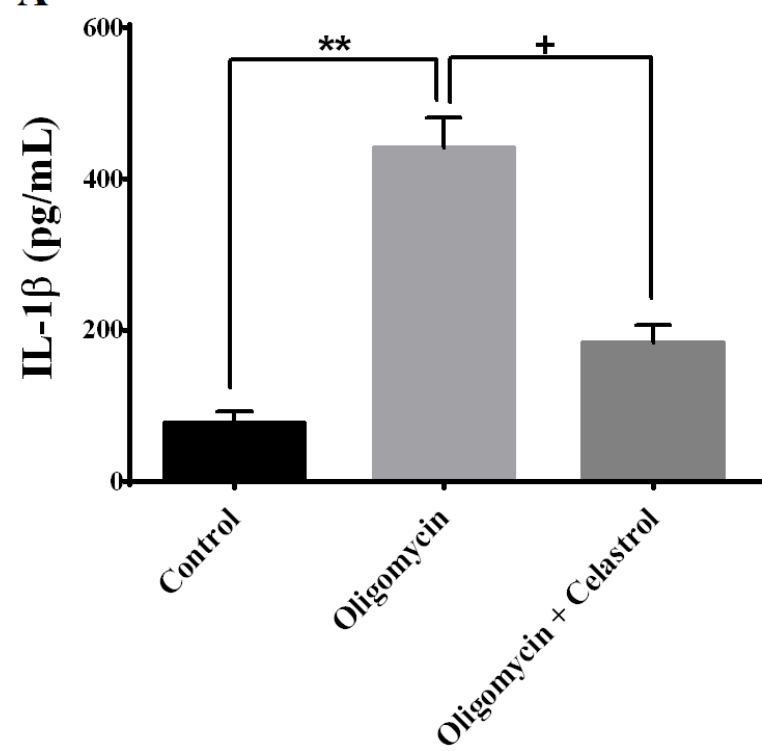

B

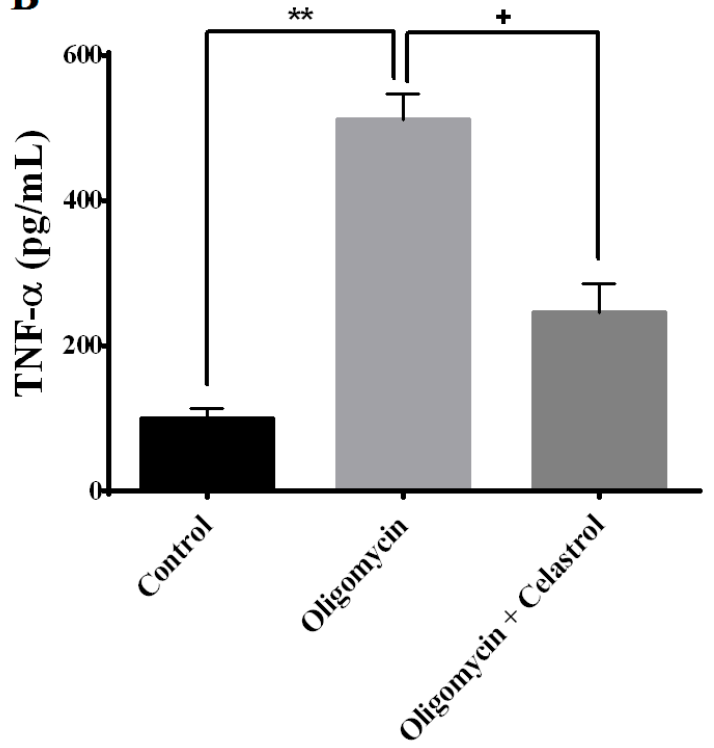

2.7. Co-Incubation of Celastrol Lead to the Restoration of Insulin-Induced Glucose Uptake Activity and Improved Insulin Signaling Cascades in Oligomycin-Treated 3T3-L1 Adipocytes

To investigate whether NF- $\kappa \mathrm{B}$ activation may play a significant role in affecting glucose metabolism of adipocytes with mitochondrial dysfunction, we first looked at the event of glucose uptake activity of 3T3-L1 adipocytes with or without treatments. Cells in 24-well plates were treated for $48 \mathrm{~h}$ with oligomycin and celastrol in growth media in the presence or absence of insulin. The result showed insulin-induced glucose uptake was 0.24 times higher than that in normal basal group, but was reduced as much as $37 \%(p<0.05)$ and $47 \%(p<0.05)$ at the basal and insulin-stimulated condition, respectively, after incubation with oligomycin for $48 \mathrm{~h}$. Co-treatment with celastrol partly reversed the glucose uptake activity of adipocytes with mitochondrial dysfunction. Insulin-induced glucose uptake was boosted by $37 \%(p<0.05)$ after co-incubation with $5 \mu \mathrm{M}$ celastrol for $48 \mathrm{~h}$ (Figure $7 \mathrm{~A})$, thus partly reverting the cell to normal phenotype relative to untreated control.

Given the importance of insulin signaling activity in adipose tissue, it is appealing to investigate the association of NF- $\mathrm{KB}$ pathways in the context of mitochondrial dysfunction by measuring insulin signaling activity and relative expression of glucose transporter protein in adipocytes. IRS 1 is a protein effector that consists of multiple tyrosine phosphorylation motifs that mediate the metabolic growth of cell towards insulin stimulation. One of the important IRS1 tyrosine residues involved in the activation of phosphoinositide 3-kinase (PI3K) relative to insulin response is Tyr612. Akt, also known as protein kinase $\mathrm{B}$ is a serine/threonine protein kinase that regulates numerous signaling pathways including proliferation, survival and metabolism. Phosphorylation of serine 473 (Ser473) residues in the hydrophobic $C$-terminal regulatory domain is largely dependent on insulin stimulation. AS160 is 
a downstream effector of Akt activation in distal insulin signaling pathways that modulate the increased translocation of cell-surface GLUT4 in 3T3-L1 adipocytes. In the present study, we showed that the phosphorylation of IRS1, Akt and AS160 under insulin stimulation was completely lessened after incubated with oligomycin for $48 \mathrm{~h}$. Meanwhile, co-treatment with celastrol under insulin stimulation significantly attenuated detrimental effect regulated by oligomycin through an elevated phosphorylation of these residue proteins (Figure 7B-D). Additionally, the expression of GLUT 4 was down-regulated while GLUT1 protein level was unaltered in adipocytes treated with oligomycin. Co-treatment of celastrol on adipocytes with mitochondrial dysfunction restored the level of GLUT 4 compared to control (Figure 7E).

Figure 7. Effects of celastrol treatment on insulin signaling cascades and glucose transporter in differentiated 3T3-L1 adipocytes with mitochondrial dysfunction. Representative Western blot of insulin signaling activity for (A) glucose uptake; (B) Tyr612 phosphorylation of IRS1; (C) Ser473 phosphorylation of Akt; (D) Thr642 phosphorylation of AS160; (E) and expression level of glucose transporter (GLUT4 and GLUT1) in whole-cell lysates were determined. Fully differentiated 3T3-L1 adipocytes were incubated in serum-free DMEM overnight then treated with $10 \mu \mathrm{g} / \mathrm{mL}$ oligomycin and $5 \mu \mathrm{M}$ celastrol for $48 \mathrm{~h}$. Insulin $(10 \mu \mathrm{g} / \mathrm{mL})$ was added into plate for $30 \mathrm{~min}$ at $37^{\circ} \mathrm{C}$. $\beta$-actin was used as loading control. Protein levels measured were normalized against $\beta$-actin. ${ }^{*} p<0.05$ vs. untreated control; ${ }^{\#} p<0.05 v s$. basal rate; ${ }^{+} p<0.05 v s$. oligomycin-treated cells.

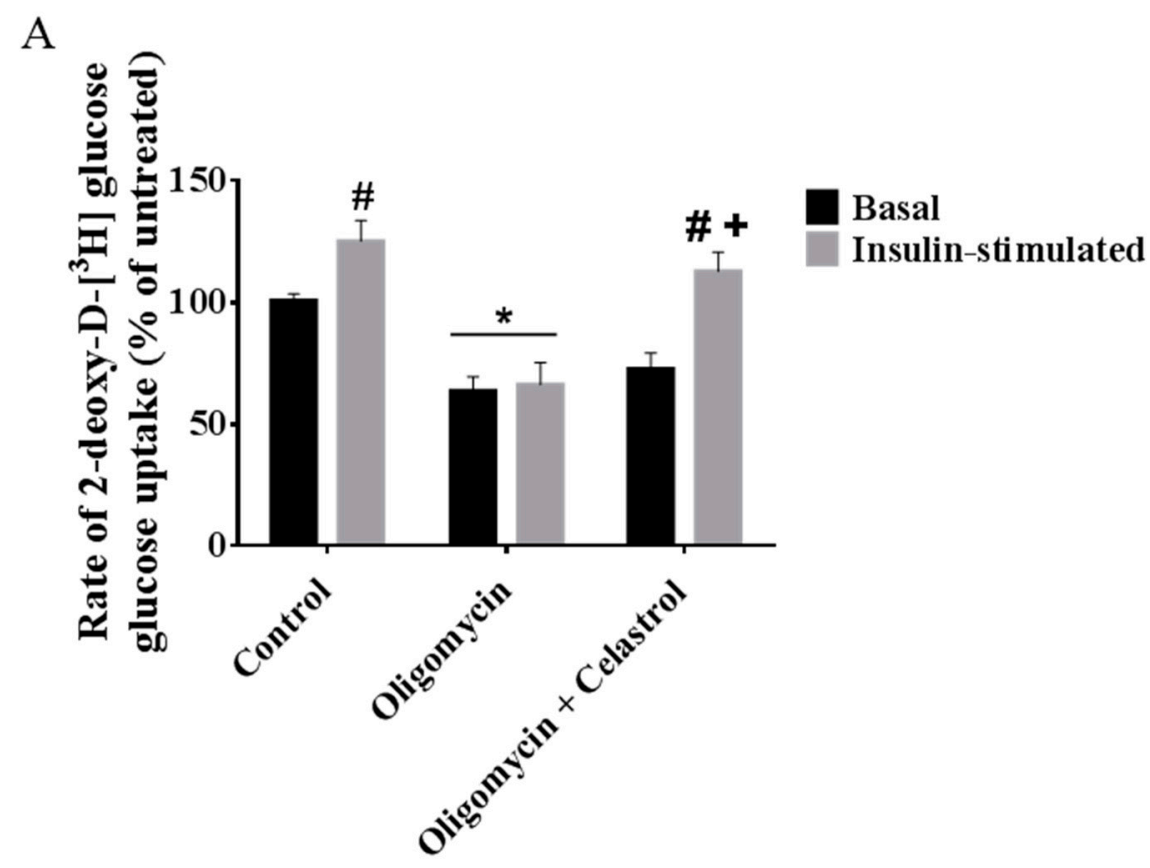


Figure 7. Cont.
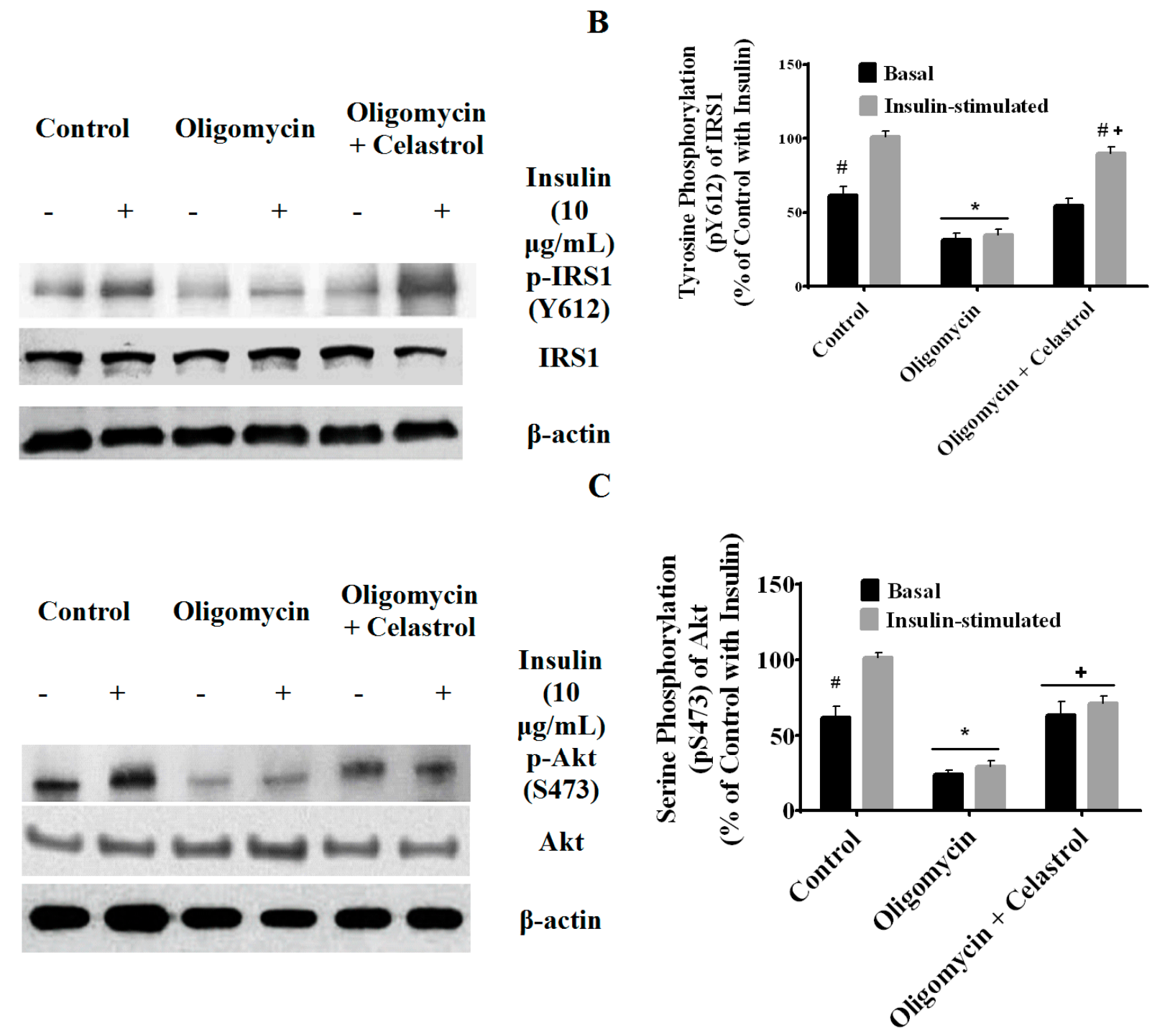

D
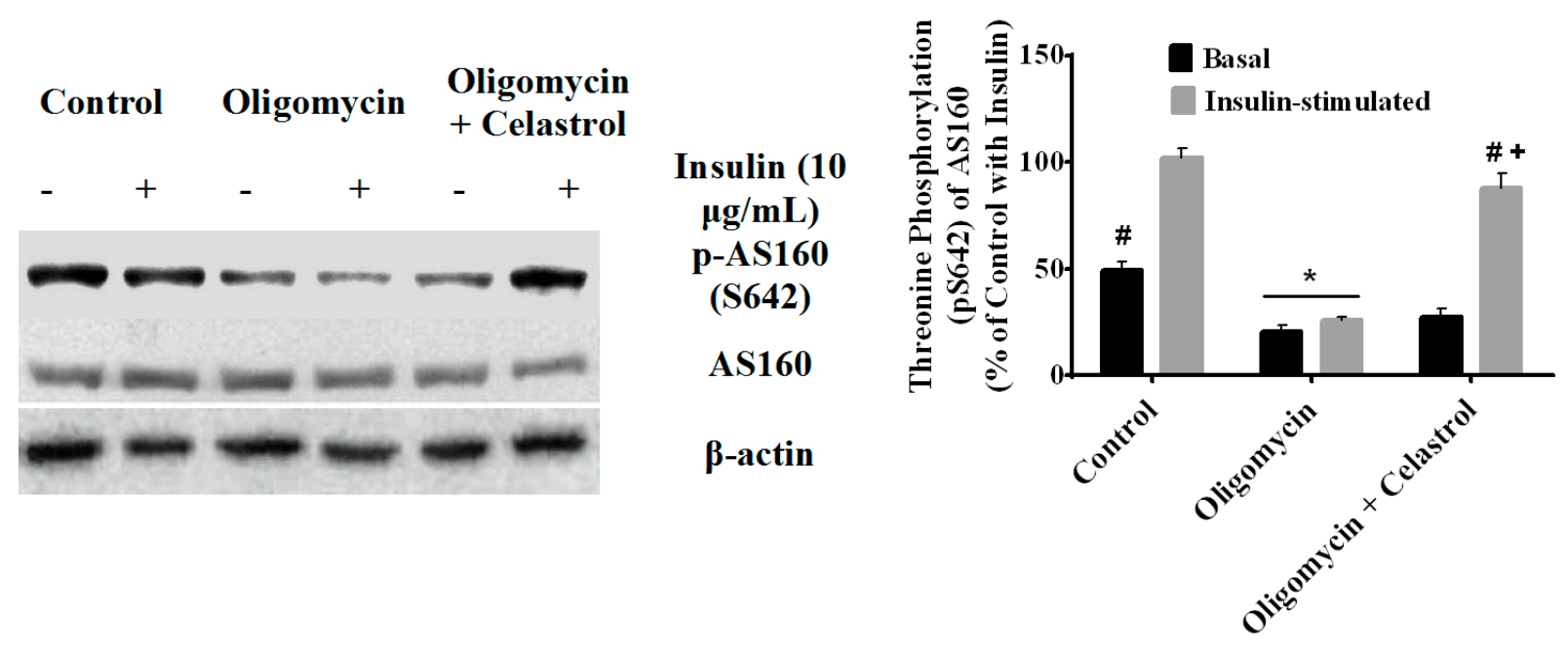
Figure 7. Cont.

$\mathbf{E}$

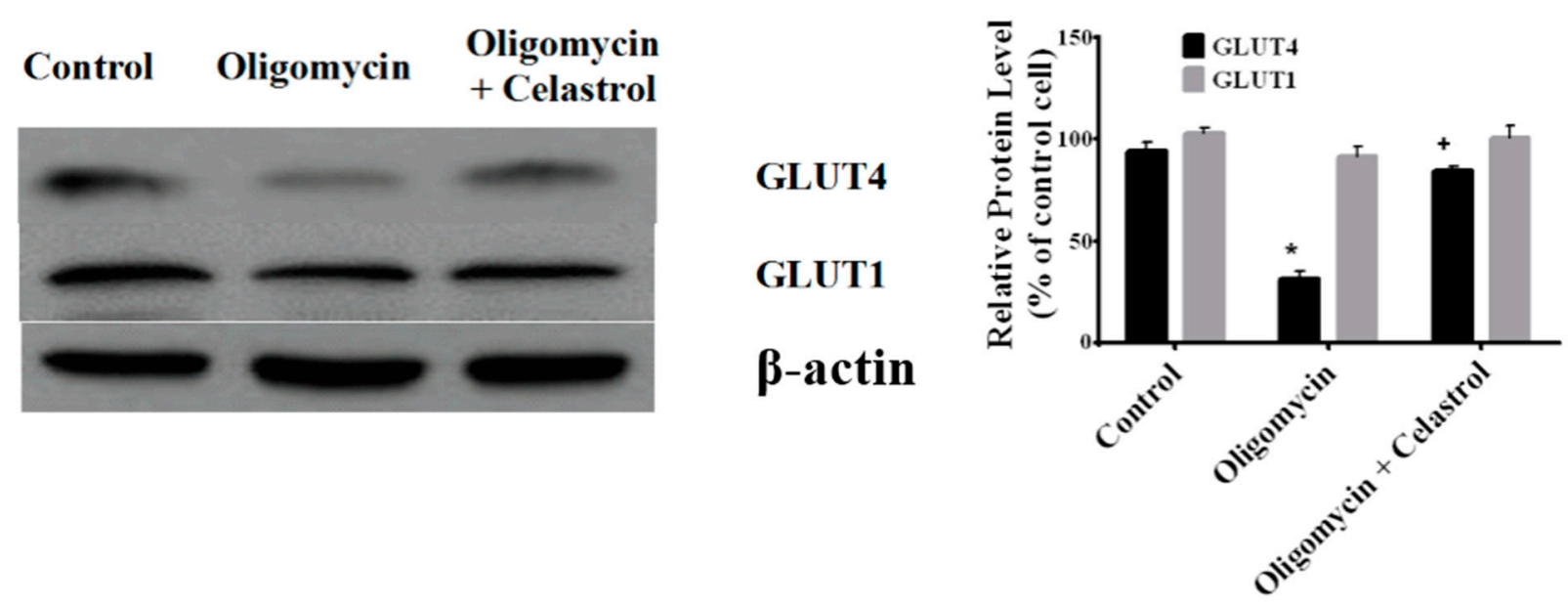

\subsection{Discussion}

In recent years, emerging evidence has been gathered to support the notion that an increase of oxidative stress, mitochondrial damage and exacerbated inflammation are among the key features of obesity and type 2 diabetes $[1,2,4]$. The concerted actions of both acute and chronic inflammation with augmented superoxide free radicals productions can lead to further reduce the ATP generation, consequently impeding insulin-signaling activities in a number of peripheral tissues. Although it is broadly appreciated that oxidative stress and inflammation lead to development of insulin resistance, the therapeutic interventions in modulating these mitochondrial dysfunction-induced inflammations are relatively scarce. Therefore, further research in orchestrating other regulatory mechanisms and its ameliorative properties may provide an insight towards effective treatments of such disorders. Activation of redox-sensitive inflammatory pathways via NF- $\kappa \mathrm{B}$ signaling by mitochondrial dysfunction has been postulated as an adaptive system of cellular stress towards overwhelmed generation of ROS [21]. One study has reported that the involvement of NF- $\kappa \mathrm{B}$ pathways inhibits adipogenesis in murine cells [28] whereas the expression of adipocyte-specific genes were down-regulated by pre-treatment with TNF- $\alpha$ via NF- $\kappa B$ pathways [29]. Nevertheless, the precise mechanism linking NF- $\kappa B$ activation and mitochondrial dysfunction in adipocytes are still rather ambiguous.

Following the recent correlation between mitochondrial dysfunction and inflammation, the present study envisaged to further determine the mechanistic effect of a major regulator inflammatory response drug, celastrol upon treatment of common mitochondrial respiratory enzyme inhibitors oligomycin on fully differentiated 3T3-L1 adipocytes. We established an in vitro model of mitochondrial dysfunction in adipocytes through impairment of ATP synthase by $10 \mu \mathrm{M}$ oligomycin treatment for $48 \mathrm{~h}$. In parallel, to discover the involvement of NF- $\mathrm{KB}$ signaling pathways activation, we co-incubated oligomycin-treated cells with $5 \mu \mathrm{M}$ celastrol for $48 \mathrm{~h}$. The dose response and time course of the cell viability were performed accordingly in order to avoid possible toxic effects of oligomycin and celastrol (Figure 1C,D). After treatment with oligomycin, we confirmed earlier findings that mitochondrial dysfunction directly affects oxidative metabolism of adipocytes in the absence and presence of insulin [30,31]. Furthermore, with the use of this in vitro model, we observed a marked improvement of metabolic functions of 3T3-L1 
adipocytes with mitochondrial dysfunction after treatment with celastrol. Our data in this study are the first to implicate the role of NF- $\kappa \mathrm{B}$ inhibition in a mechanism of insulin resistance in adipocytes induced by mitochondrial dysfunction.

Studies have recently demonstrated an association of mitochondrial dysfunction in adipocytes of subjects with a positive family history of diabetes, and in animals with obesity-associated type 2 diabetes [32,33]. Accordingly, uncontrolled generation of ROS in the event of mitochondrial dysfunction in other cell types have been linked to the stimulation of inflammatory signaling pathways via NF- $\kappa \mathrm{B}$ activation [22]. Low-grade inflammatory and matrix degradation responses via mitochondrial $\mathrm{Ca}^{2+}$ exchange, ROS generation, and NF- $\mathrm{BB}$ activation may also contribute to the development of mitochondrial dysfunction [20]. The induction of mitochondrial dysfunction via inhibition of mitochondrial ATP synthase, oligomycin, significantly potentiates the cytokine-induced inflammatory response in normal synovial fibroblasts with an increase of $\mathrm{PGE}_{2}$ and IL-8 release. The authors evidenced that this inflammatory mechanism is regulated via ROS production and NF- $\mathrm{B}$ activation [34]. In other cell types, the impairment of mitochondrial functions was also resulted in over-production of ROS, leading to the cytotoxicity progression with an accumulated inflammatory cytokines [35]. Consistent with these findings, a recent study utilizing integrative approach combining in vivo and in vitro revealed that an augmented expression of inflammatory genes is implicated in the enhanced sensitivity of NF- $\kappa \mathrm{B}$ binding site to the promoter region of the cell in the context of mitochondrial dysfunction [22,36]. Similarly, with regard to the latter possibility in the mechanism of mitochondrial dysfunction, we have determined the effects of celastrol on differentiated 3T3-L1 adipocytes treated with oligomycin. A significant enrichment of intracellular ATP concentration with reduced ROS production was observed. In addition, an elevated mitochondrial membrane potential was detected in the celastrol-treated cells with oligomycin, suggesting the involvement of NF- $\mathrm{BB}$ signaling pathways in modulating such metabolic perturbations (Figure 2A-C).

As reduced mitochondrial functions with altered morphology are associated with mitochondrial dynamics, we next investigated the effects of celastrol on the expression of proteins responsible for mitochondrial fusion and fission. Mitochondria are dynamic organelles that frequently undergo fusion and fission in order to exchange power and content. The aberrant mitochondrial function indicates an imbalance of the cellular bioenergetics affecting mitochondrial fusion and fission. Mfn1 and Mfn2 are the key enzymes that involve in mitochondrial fusion via GTPase activity [37] while Drp1 is the main target protein participates in the mitochondrial fission in regards to mitochondrial division, stress response and apoptosis [38]. At present, the protein levels of Mfn1 and Drp1 were up-regulated in the events of mitochondrial dysfunctions of adipocytes while $\mathrm{mfn} 2$ protein level remained unchanged after treatment with oligomycin (Figure 3A-C). Gao and colleagues observed that the metabolic expression of Mfn1 and Drp1 in 3T3-L1 adipocytes was greatly altered in the high glucose and high free fatty acids while the level of Mfn2 was unaltered after all treatments [16]. Later, the same group also identified treatment with TNF- $\alpha$ on 3T3-L1 adipocytes affects mitochondrial dynamics of Mfn2 and Drp1 level whereas the expression of Mfn1 protein level was not affected [15]. The differences of the findings in both studies were not fully elucidated, as the metabolic regulation of mitochondrial fusion and fission are too complex to be understood. The authors believed that the changes in mitochondrial fusion and fission here are still worthy of further detailed investigation. Recently, another report [39] suggested that enforced mitochondrial hyperfusion by expressing a dominant-negative mutant of Drp1 or of MARCH5 
resulted in the activation of NF- $\kappa \mathrm{B}$ inflammatory signaling pathways in an activated kinase-1 (TAK1) and IKK-dependent manner, through the mitochondrial E3 ubiquitin ligase activator of NF- $\kappa \mathrm{B}$ (MULAN). The study has concluded that mitochondria through mitochondrial fusion and fission convert the stress signal into cellular response via activation of NF-kB pathways [39]. This is consistent with our result on identifying the roles of NF- $\mathrm{BB}$ activation in mitochondrial dynamics of adipocytes with mitochondrial dysfunction. We observed that co-incubation of celastrol in oligomycin-treated cells significantly increased and reduced the expression of Mfn1 and Drp1 protein level, respectively, while expression of $\mathrm{mfn} 2$ was unaffected (Figure $3 \mathrm{~A}-\mathrm{C}$ ).

It is of paramount importance to understand that emerging studies have started to propose the inflammatory signaling pathways mediated by activation of IKK- $\beta / N F-\kappa B$ pathways and other transcription factors are the central arbitrator in understanding oxidative stress responses in obesity-related conditions [6]. In view of that, a report utilizing obese $d b / d b$ mice found that enhanced NF- $\kappa$ B activity was coupled with intensified oxidative stress as demonstrated by abnormal accumulation of mitochondrial superoxide productions [40]. Likewise, this complex interaction is also evidenced by our data showing that NF- $\mathrm{BB}$ inhibitor significantly improved the oxidative metabolism of adipocytes treated with ATP synthase inhibitor through a reduced oxidative stress in adipocytes with mitochondrial dysfunction. The accumulation of cellular DNA damage either from nucleus and mitochondria is thought to contribute to aging process mediated via changes in redox status and oxidative stress-induced inflammatory responses [41]. Several studies have revealed that diminished mitochondrial oxidative phosphorylation and ATP production following mtDNA damage, and oxidative stress are collectively contribute to the co-regulation of $\mathrm{NF}-\kappa \mathrm{B}$ and inflammasome-mediated inflammatory responses activation, precede the development of type-2 diabetes mellitus [42-44]. The involvements of advanced glycation end (AGE) products may also affect the redox status of inflammatory signaling pathways. Treatment with glycolaldehyde-derived AGE3 on human aortic endothelial cells results in the elevated $8-\mathrm{OHdG}$ formation and TNF- $\alpha$ concentration. The authors also observed that an inhibition of NF- $\kappa \mathrm{B}$ activation suppressed AGE3-induced 8-OHdG formation, implying that sustained activation of NF- $\mathrm{kB}$ might be play pivotal roles for endothelial dysfunction in diabetes [45].

Carbonylation is a type of protein oxidation involving non-reversible direct oxidation of the side chains of cysteine, histidine, and lysine residues by lipid peroxidation end products such as 4-hydroxy and 4-oxononenal [46]. An elevation of protein carbonylation is observed in the subcutaneous human adipose tissue [47] and adipose tissue of diet-induced obese mice [48]. The upsurge of protein carbonylation level was revealed to play a major instigating role in the inflammation related pathways. Chronic treatment of 3T3-L1 adipocytes with pro-inflammatory cytokines TNF- $\alpha$ lead to development of mitochondrial dysfunction, protein carbonylation and lipid peroxidation [48]. This is supported by another observation showing the oxidation of thioredoxin (a class of small redox proteins) that result in the release and activation of apoptosis signal-regulating kinase 1 (ASK1) have been linked to progression of mitochondrial dysfunction-induced inflammation. This process initiate a cascade of phosphorylation events culminating in the activation of c-Jun $N$-terminal kinases (c-JNKs) and the NF- $\mathrm{BB}$ pathway as well as serine phosphorylation of IRS1, giving rise to the formation of oxidized lipid and proteins [49].

Lipid peroxidation is an activated metabolic process that signals the redox imbalance causes the activation of intracellular inflammatory signaling pathways. 4-hydroxy-trans-2-nonenal (HNE), malondialdehyde and acrolein are among the common by-products of lipid peroxidation that were shown 
to activate various signaling intermediates and regulate cellular dysfunctions involving redox-sensitive transcription factor NF- $\kappa$ B [50]. A study utilizing Male Sprague-Dawley rats has shown that inhibition of lipid peroxidation by administration of raxofelast results in a significant reduction of MDA and declined myeloperoxidase (MPO) activity through suppression of pancreatic NF- $\mathrm{BB}$ activation and the TNF- $\alpha$ mRNA levels [51]. Moreover, another study signified that the activation of a redox-sensitive transcription factor NF- $\mathrm{BB}$ signaling pathways in the event of lipid peroxidation lead to the posttranslational modification of proteins and DNA leading to cytotoxicity and genotoxicity [50]. These observations were in parallel with our data showing that amplified level of DNA oxidative damage, protein carbonylation and lipid peroxidation was observed in the oligomycin-treated cell but inhibited by celastrol treatment for $48 \mathrm{~h}$ (Figure 4A). These evidences indicated that celastrol is a potent inhibitor of oxidative stress-induced activation of NF- $\kappa$ B in 3T3-L1 adipocytes.

Inadequate suppression of lipolysis in adipose tissues and boosted delivery of free fatty acids into ectopic tissues (e.g., muscle, pancreas and liver) play a key role in the exacerbation of insulin resistance [2]. Several pro-inflammatory cytokines has been shown to induce enhanced lipolysis in adipocytes. Co-treatment of 3T3-L1 adipocytes with IL-6 lead to augmented lipolysis with diminished ATP content [52]. The stimulatory effects of TNF- $\alpha$ on the cellular lipolysis was also documented via the mitogen-activated protein kinase (MAPK) family involving extracellular signal-related kinase (ERK) and JNK in different type of cells [53]. Incubation of primary cultures of human adipocytes in the presence of a cell-permeable peptide that inhibits NF- $\kappa B$ signaling showed the abolishment of the nuclear translocation of NF- $\kappa \mathrm{B}$ in the event of TNF- $\alpha$-induced lipolysis [54]. Our data contributes to a new finding that an intensification of lipolysis through the impairment of adipocyte ATP synthase may be regulated by the activation of NF- $\kappa$ B signaling pathways (Figure 5A,B).

Furthermore, the data presented in this study also demonstrated that suppression of IKK $-\beta / N F-\kappa B$ signaling pathway by celastrol may also give rise to the diminished intracellular accumulation of lipid droplets in 3T3-L1 adipocytes treated with oligomycin (Figure 5C-G). Abnormal lipid deposition in various peripheral tissues has been proposed as one of detrimental occasions in the progression of obesity and insulin resistance-related diseases [3]. In normal physiological conditions, the relative levels of fatty acids are constantly maintained at the balance of utilization and deposition. Abnormal accumulation of lipids due to enlarged adipocytes mass resulted in a disproportionate rate of fatty acid oxidation, causing the cellular deposition of various lengths of acylcarnitine fatty acids. The incomplete fatty acid oxidation in mitochondria is prominent to be observed as the efficiency of mitochondrial functions was blunted. It is not surprising that treatment of adipocytes with oligomycin may result in excess intracellular lipid accumulations due to aberrant mitochondrial functions to metabolize these lipid intermediates. The dysfunctional lipid storage in adipocytes are significantly correlated to the downstream effects of TLR4 stimulation via activation of NF- $\mathrm{BB}$ transcription factor, which then triggers the transcription of many pro-inflammatory genes [55].

Adipose tissue is now appreciated as one of the important endocrine tissues that secrete hormones and circulating cytokines such as TNF- $\alpha$ and IL-1 $\beta$. The relative level of these pro-inflammatory cytokines were elevated in obese and diabetic people [14]. High levels of recombinant TNF- $\alpha$ and IL-1 $\beta$ in co-cultured 3T3-L1 adipocytes with primary peritoneal mouse macrophages were identified to inhibit the expression of GLUT4 in 3T3-L1 adipocytes [56]. Notably, excessive production of pro-inflammatory cytokines is characterized by defective mitochondrial functions, oxidative stress with 
over-generation of ROS [7]. Moreover, the activation of transcription factor NF- $\kappa \mathrm{B}$ was proved to be a target of oxidative stress. Direct exposure of $\mathrm{H}_{2} \mathrm{O}_{2}$ in certain cell types was shown to be an effective inducer of NF- $\kappa \mathrm{B}$ activation [57]. The linkage of oxidative stress and NF- $\kappa \mathrm{B}$ activation are connected to the elevated production of pro-inflammatory cytokines that lead to inhibition of intracellular insulin signaling activities in a number of peripheral tissues [5]. These data suggest that elevated pro-inflammatory cytokines are strongly connected to the onset of oxidative stress induced insulin resistance. Our study showed that the concentration of IL- $1 \beta$ and TNF- $\alpha$ was higher in adipocytes with mitochondrial dysfunction than untreated cells. The pharmacologic modulation of NF- $\kappa \mathrm{B}$ activation with celastrol significantly prevented up-regulation of TNF- $\alpha$ and IL- $1 \beta$ level in oligomycin-treated cells, supporting the previous findings that NF- $\kappa$ B regulate the enhanced expression of IL- $1 \beta$ and TNF- $\alpha$ correlated with mitochondrial dysfunction [1]. These results have at least provided solid evidence to substantiate that inhibition of IKK- $\beta / \mathrm{NF}-\kappa \mathrm{B}$ inflammatory signaling pathways play a role in modulating mitochondrial dysfunction-induced insulin resistance in 3T3-L1 adipocytes with inflammation (Figure 6A,B).

On the other hand, the attenuation effects of adipocytes with mitochondrial dysfunction by celastrol in this study are not limited to the abovementioned findings, but also significantly implicated in the restoration of insulin induced-glucose uptake and enhanced insulin-signaling activity (Figure 7A-D). It has been established that adipose tissues with mitochondrial dysfunction that occurs in the metabolic syndrome are manifested with impaired glucose homeostasis and insulin insensitivity [32,34]. The progressive enlargement of adipocytes mass with an infiltration of macrophage may lead to the over-production of pro-inflammatory cytokines with hypoxia-induced a decline in glucose utilization rate [58]. Multiple in vitro studies revealed that impaired glucose homeostasis relatively results from reduced mitochondrial functions. Co-treatment of 3T3-L1 adipocytes with high concentration of glucose and free fatty acids was shown to stimulate mitochondrial dysfunction [16]. In addition, a significant decrease in insulin-stimulated glucose uptake was observed in 3T3-L1 adipocytes with mitochondrial dysfunctions after four days exposure of pro-inflammatory cytokine TNF- $\alpha$ [15]. Another group showed that [31] the induction of mitochondrial dysfunction and over-production of ROS in adipocytes by adding mitochondrial inhibitors and knockdown of mitochondrial transcription factor A (mtTFA), respectively result in the lowered glucose uptake and impaired insulin signaling activity upon insulin stimulation in adipocytes. They also noticed that the expression of GLUT4 and secretion of adiponectin was significantly blunted in adipocytes with mitochondrial dysfunctions. Mauro and colleagues have proposed that an activation of NF- $\kappa \mathrm{B}$ may affects the cellular reprogramming of bioenergetics pathways involving mitochondrial respiration and glucose utilization [59]. Our results first illustrated that inhibition of NF- $\mathrm{KB}$ pathways by incubating celastrol in 3T3-L1 adipocytes with mitochondrial dysfunction improved glucose uptake activity. Enhanced insulin signaling pathways were significantly observed via boosted phosphorylation of Tyr612 residue of IRS1, Ser473 residue of Akt/PKB, Thr642 residue of AS160 (Figure 7A-D), possibly implying this inflammatory signaling pathway is implicated in the pathogenesis of insulin resistance in adipose tissue with mitochondrial dysfunction.

The relative translocation of glucose transporter over the plasma membrane from intracellular storage vesicles within insulin-sensitive tissues is a major regulatory process for the maintenance of blood glucose homeostasis. GLUT4, also called the "insulin-regulated glucose transporter", is one of the key proteins involved in the glucose uptake activity relative to insulin stimulation through an ATP-independent, facilitative diffusion mechanism. High expression of this membrane protein was 
evidenced in adipose tissues and skeletal muscle [60]. Particularly, reduced expression level of GLUT4 is associated with the pathogenesis of type 2 diabetes where transgenic mice with severe alteration of GLUT4 level developed insulin resistance with impaired glucose homeostasis [61]. Our result revealed that an inhibition of ATP synthase in adipocytes was led to a significant depletion of GLUT4 level (Figure 7E). Concurrent increase of ROS production has been suggested as one of the metabolic insults that down-regulate the expression of GLUT4 level upon oligomycin treatment [31]. Oxidative stress elicited by mitochondrial dysfunction may contribute to the insulin insensitivity of adipocytes. Co-incubation with celastrol on 3T3-L1 adipocytes with mitochondrial dysfunction significantly abrogated the effect of oligomycin on GLUT4 protein expression in 3T3-L1 adipocytes (Figure 7E). Therefore, it can be exemplified that the amelioration properties possess by celastrol on the inhibition of NF- $\kappa$ B pathways are correlated with the translocation of GLUT4. Our study is in agreement with another report utilizing streptozotocin-induced diabetic Sprague-Dawley rats by specifying that the inhibition of $\mathrm{NF}-\kappa \mathrm{B}$ activity elevates the expression of GLUT4 in uterus of diabetic rats [62], indicating the roles of $\mathrm{NF}-\kappa \mathrm{B}$ may be allied with the relative expression of GLUT-4.

GLUT1 is another type of membrane protein in glucose transporter family that ubiquitously express for indicating basal glucose uptake. The stimulation of AMP-activated protein kinase (AMPK) is reportedly coupled to the enhancement of GLUT1-mediated glucose transport [63]. Furthermore, activation of ERK also leads to the up-regulated expression of GLUT1, resulting in the elevation of basal glucose uptake in the absence of insulin stimulation. Presently, we found no significant changes on the GLUT1 protein level neither in the oligomycin treated cell nor with co-treatment of celastrol. Our data is consistent with the study done by Wang et al. [31]. We believe that the mechanism behind this observation is due to intrinsic function of GLUT1 to compensate the maintenance of relative basal glucose uptake in the cell. It was reported that an enhancement of GLUT1 protein level was observed in human cells with mitochondrial dysfunction [64]. Our result indicated that the expression of this protein level was unchanged, specifying that GLUT1 was not involved in NF- $\kappa$ B pathways of adipocytes with mitochondrial dysfunction (Figure 7E).

The primary goal of our work is to investigate the in-vitro mechanism of NF- $\mathrm{BB}$ inhibition in the development of mitochondrial dysfunction induced insulin resistance in differentiated 3T3-L1 adipocytes. The limitation of the present study is the use of in-vitro adipocytes to study the effects of NF- $\mathrm{B}$ pathway inhibition in adipocytes with mitochondrial dysfunction. It is clear from our own understanding that further in vivo study utilizing genetically modified cells (knockout, over or down-regulation of the NF- $\mathrm{B}$ gene) will better characterize the roles of NF- $\kappa \mathrm{B}$ pathways in the development of mitochondrial dysfunction-induced insulin resistance. However, we believe that our works have much value of expositing the specific mechanistic interaction of this regulatory pathway in the development of such perturbations. We hope that this study will be an important reference for therapeutic intervention of diabetes, especially for those diabetes patients with inflammatory disease. Further experimental methodologies in systems-based approaches should be continued to explore the underlying mechanisms of such impairments. The systemic interaction involving whole body homeostasis may represent the holistic assessment of disease mechanisms from the metabolic understanding point of views [65]. 


\section{Experimental Section}

\subsection{Cell Culture}

3T3-L1 pre-adipocytes were purchased from the American Type Culture Collection (ATCC) (Manassas, VA, USA) and grown in Dulbecco's Modified Eagle Medium (DMEM) with high glucose (Gibco, Carlsbad, CA, USA) supplemented with $10 \%$ of fetal calf serum (FCS) and 1\% of penicillin, streptomycin (antibiotics) (Gibco). The cells were sub-cultured every three days before the culture becomes fully confluent, which are about $70 \%-80 \%$ of sub-confluent culture. The standard seeding density used was $2 \times 10^{5}-4 \times 10^{5}$ cells $/ \mathrm{cm}^{2}$ and seeded in a $75 \mathrm{~cm}^{2}$ flask followed by incubated at $37{ }^{\circ} \mathrm{C}$ in the humidified atmosphere of $5 \% \mathrm{CO}_{2}$. The 3T3-L1 pre-adipocytes were differentiated into adipocytes using a standard protocol [66]. Briefly, the cells were incubated for $48 \mathrm{~h}$ before undergo full differentiation. Later, cells were maintained in regular growth medium supplemented with adipogenic cocktail containing MDI (0.5 mM 3-isobutyl-1-methyl-xanthine (IBMX), $0.25 \mu \mathrm{M}$ dexamethasone and $1 \mu \mathrm{g} / \mathrm{mL}$ insulin) (Sigma, St. Louis, MO, USA) for 2 days. On the 4th day, the media was replaced for every two days with DMEM containing 10\% fetal bovine serum (FBS) till 8 th day of adipocytes differentiation. In differentiated adipocytes, certain experiments involved stimulation with insulin $(10 \mu \mathrm{g} / \mathrm{mL})$ for $30 \mathrm{~min}$ at $37^{\circ} \mathrm{C}$. To avoid confounding variables, the protocol used for insulin stimulation was similar to all types of experiments involving insulin-signaling activities in order. The insulin stimulation is necessary to 3T3-L1 adipocytes in order to measure the glucose uptake and its metabolic activities relative basal level. As insulin resistance is associated with reduced glucose uptake and deteriorated insulin-signaling activities, the experimental approach with insulin stimulation is crucial to observe the underlying effects of such inhibitors on 3T3-L1 adipocytes. According to the standard protocol used widely for treating 3T3-L1 adipocytes, pharmacological level of insulin $(10 \mu \mathrm{g} / \mathrm{mL})$ induce mitosis in adipocytes and $30 \mathrm{~min}$ treatment prior to any assays would be useful to observe the effects on insulin-signaling activities [67]. Therefore, insulin dose of $10 \mu \mathrm{g} / \mathrm{mL}$ was chosen for all experiments involving insulin stimulation effects.

\subsection{Oligomycin and Celastrol Treatment}

The establishment of mitochondrial dysfunction-mediated insulin resistance in 3T3-L1 adipocytes was performed as previously described [30]. On the 8th day after induction, fully differentiated 3T3-L1 adipocytes were serum starved for $18 \mathrm{~h}$. The goal of serum starvation is to synchronize the cell cycle. The cells were serum starved before the treatment was performed. Then, the cell-based assays were performed accordingly. Oligomycin (Sigma), ATP synthase inhibitor was used to induce mitochondrial dysfunction in adipocytes. Cells were treated with oligomycin with or without celastrol (Sigma). The cells without treatment were used as controls. Media in control and treated cells were replaced daily, and assays were executed after 9th or 10th day of post-differentiations.

\subsection{Measurement of Cell Viability}

Cell viability was assessed by MTT assay. 3T3-L1 adipocytes were grown in 96-well plates. Cells were then incubated with varying concentration of oligomycin $(5,10,20$ and $30 \mu \mathrm{M})$ with or without celastrol 
$(5,10,20$ and $30 \mu \mathrm{M})$ in DMSO. Our preliminary study revealed that the use of DMSO in growth media did not affect the cell viability of adipocytes differentiation at a final concentration of $0.1 \%$ (data not shown). To ensure the integrity of adipocytes functions, the optimal dose for each inhibitor that did not significantly affect cell viability was chosen for time-course evaluation. The time-course dependent was evaluated for each optimal dose (12, 24, 36 and $48 \mathrm{~h})$. Briefly, phosphate buffer saline (PBS) was used to dissolve $5 \mathrm{mg} / \mathrm{mL}$ MTT before filtered through $0.2 \mu \mathrm{M}$ micro-filter and will be stored at $4{ }^{\circ} \mathrm{C}$. Fully differentiated 3T3-L1 adipocytes were washed out with PBS. $10 \mu \mathrm{L}$ of MTT stock solution was prepared and subsequently added into each well and incubated for $3-4 \mathrm{~h}$ at $37^{\circ} \mathrm{C}$. After that, $200 \mu \mathrm{L}$ of dimethyl sulfoxide (DMSO) was transferred into each well to dissolve the insoluble purple formazan product into coloured solution. The absorbance of the colored solution was measured at the wavelength of $570 \mathrm{~nm}$ and reference wavelength of $630 \mathrm{~nm}$ using the ELISA plate reader (Erba LisaScan II, Mannheim, Germany). Optical densities of treated cells were normalized to controls. Each condition was performed in triplicate.

\subsection{Intracellular ATP Concentration}

Intracellular ATP concentrations were assayed by using a calorimetric ATP Assay Kit (KA0806; Abnova Corporation, Walnut, CA, USA). The cells were lysed in $100 \mu \mathrm{L}$ ATP Assay Buffer followed by deproteinization of cell lysates using $10 \mathrm{kDa}$ Spin Column. Using ATP standard, intracellular ATP concentrations were then determined with ELISA plate reader measured at the wavelength of $570 \mathrm{~nm}$ and normalized to protein concentrations.

\subsection{Measurement of Mitochondrial Membrane Potentials ( $\triangle \Psi m)$}

The measurement of mitochondrial membrane potential were determined using the mitochondria-specific lipophilic cationic fluorescence dye 5,5',6,6'-tetrachloro-1,1',3,3'-tetraethylbenzimi-dazolylcarbocyanine iodide (JC-1) Detection Kit (KA1324; Abnova Corporation) following the manufacturer's instruction. Briefly, treated $1 \times 10^{6}$ cells were plated on 96-well black culture plate in $100 \mu \mathrm{L}$ culture medium in a $\mathrm{CO}_{2}$ incubator overnight at $37^{\circ} \mathrm{C}$. After then, $10 \mu \mathrm{L}$ of the JC-1 Staining Solution were added to each well and incubated in $\mathrm{CO}_{2}$ incubator at $37{ }^{\circ} \mathrm{C}$ for $15-30 \mathrm{~min}$. The plate was centrifuged for $5 \mathrm{~min}$ at $400 \times g$ at room temperature and supernatant was discarded. $100 \mu \mathrm{L}$ of Assay Buffer was added to each well and ready for analysis by a fluorescent plate reader (Promega, Madison, WI, USA). J-aggregates were formed in healthy cells with excitation and emission at 560 and $595 \mathrm{~nm}$, respectively. In unhealthy cells, JC-1 exists as monomers that was excited at $485 \mathrm{~nm}$ and emits at $535 \mathrm{~nm}$.

\subsection{Mitochondrial Superoxide Measurement}

Cells in black-walled 96-well plates were treated with oligomycin and celastrol for $48 \mathrm{~h}$ as described above. ROS production in adipocytes was measured by incubating cells with $1 \mu \mathrm{M}$ Mitosox Red (Invitrogen Molecular Probes, Carlsbad, CA, USA) for $30 \mathrm{~min}$ at $37^{\circ} \mathrm{C}$. After two times washes with PBS, cells were collected and used for fluorescence analysis using a multimode plate reader at an excitation wavelength of $510 \mathrm{~nm}$ and an emission wavelength of $580 \mathrm{~nm}$. 


\subsection{Immunoblotting}

Western blotting analysis was carried out as previously described [68]. Briefly, after treatments, the cells were washed twice with Krebs-Ringer HEPES buffer and homogenized with protein lysis buffer (50 mM Tris pH 7.5, 1 mM EDTA, 1 mM EGTA, 10\% glycerol, 1\% triton X-100, $50 \mathrm{mM} \mathrm{NaF,} 5 \mathrm{mM}$ $\mathrm{Na}_{4} \mathrm{P}_{2} \mathrm{O}_{7}, 1 \mathrm{mM} \mathrm{Na} \mathrm{VO}_{4}, 1 \mathrm{mM}$ DTT) containing protease and phosphatase inhibitors. The cell lysate was incubated on ice for about $1 \mathrm{~h}$ with constant mixing. Proteins concentrations were quantified using a Pierce ${ }^{\mathrm{TM}}$ BCA Protein Assay Kit (Thermo Scientific, Waltham, MA, USA). To be used as a whole protein, supernatants were collected after centrifugation at $16,000 \times \mathrm{g}$ for $20 \mathrm{~min}$ at $4{ }^{\circ} \mathrm{C}$. The aliquots of whole protein was separated on odecyl sulfate-polyacrylamide gel electrophoresis (SDS-PAGE), and transferred to nitrocellulose membranes (Whatman, London, UK). Membrane were blocked with Tris-buffered saline/Tween-20 (TBST, $0.14 \mathrm{~mol} / \mathrm{L} \mathrm{NaCl}, 0.02 \mathrm{~mol} / \mathrm{L}$ Tris base ( $\mathrm{pH} 7.6$ ), and $0.1 \%$ Tween) containing $5 \% \mathrm{w} / \mathrm{v}$ bovine serum albumin (BSA) for $1 \mathrm{~h}$ at room temperature. After then, the membranes were incubated overnight at $4{ }^{\circ} \mathrm{C}$ with specific primary antibodies of interest, at the dilution indicated, in TBST: NF-кB p65 (1:1000, Cell Signaling Technology, Danvers, MA, USA), mfn1 (1:1000, Santa Cruz Biotechnology, Santa Cruz, CA, USA), mfn2 (1:1000, Santa Cruz Biotechnology), drp1 (1:1000, Santa Cruz Biotechnology), pY612-IRS1 (1:1000, Upstate Biotechnology, Lake Placid, New York, NY, USA), IRS1 (1:1000, Upstate), pS473-Akt (1:1000, Cell Signaling Technology), Akt (1:1000, Cell Signaling Technology), pS462 AS160 (1:1000, Cell Signaling Technology), AS160 (1:1000, Cell Signaling Technology), GLUT4 (1:1000, Cell Signaling Technology), GLUT1 (1:1000, Novus Biologicals, Littleton, CO, USA) and $\beta$-actin (1:1000, Cell Signaling Technology) at room temperature. Membranes were washed with TBST at a dilution of 1: 10,000 for $1 \mathrm{~h}$ at room temperature before the corresponding horseradish peroxidase (HRP)-conjugated secondary antibodies (Pierce Biotechnology, Rockford, IL, USA) were treated. Specific immune complexes were detected by chemiluminescence using ECL plus kits (Amersham, Piscataway, NJ, USA), visualized using ChemiDoc ${ }^{\text {TM }}$ XRS + (Bio-Rad, Hercules, CA, USA) with Image Lab ${ }^{\text {TM }}$ software (Bio-Rad, Hercules, CA, USA) and quantified by using a standard densitometry.

\subsection{Measurement of DNA Oxidative Damage and Lipid Peroxidation}

8-OHdG is a ubiquitous marker of oxidative stress-mediated DNA damage, was quantified using the OxiSelect ${ }^{\mathrm{TM}}$ Oxidative DNA Damage ELISA Kit (Cell Biolabs, San Diego, CA, USA) as previously described [69]. The lipid peroxidation was assessed by measuring malondialdehyde (MDA) as an end product of lipid peroxidation using Lipid Peroxidation (MDA) Assay Kit (Sigma) according to the manufacturer's protocols.

\subsection{Protein Carbonylation}

Protein carbonyls were detected using Protein Carbonyl Content Assay Kit (Cayman, Ann Arbor, MI, USA). Briefly, cells were washed with PBS and centrifuged to $1000-2000 \times \mathrm{g}$ for $10 \mathrm{~min}$ at $4{ }^{\circ} \mathrm{C}$. The cell pellet was sonicated on ice in $2 \mathrm{~mL}$ of cold buffer containing $50 \mathrm{mM}$ phosphate, pH 6.7 with $1 \mathrm{mM}$ EDTA. Then, the mixture was centrifuged again at $10,000 \times \mathrm{g}$ for $15 \mathrm{~min}$ at $4{ }^{\circ} \mathrm{C}$ and supernatant was removed and stored on ice. After that, $800 \mu \mathrm{L}$ of DPNH and $2.5 \mathrm{M} \mathrm{HCI}$ was added to sample and control 
tubes, respectively. The tubes were incubated for $1 \mathrm{~h}$ at dark room temperature followed by the addition of $1 \mathrm{~mL}$ of $20 \%$ TCA to each tube on ice. All tubes were centrifuged at $10,000 \times \mathrm{g}$ for $10 \mathrm{~min}$ at $4{ }^{\circ} \mathrm{C}$ and supernatant was discarded. The cell pellet was re-suspended in $1 \mathrm{~mL}$ of (1:1) ethanol/ethyl acetate mixture. These steps were repeated three times in order to remove cellular debris. After the final wash, the protein pellet was re-suspended in $500 \mu \mathrm{L}$ of guanidine hydrochloride and centrifuged at the same speed as stated above to remove any leftover debris. Each $220 \mu \mathrm{L}$ of sample and control tubes were transferred to 96-well plates and measured at the absorbance of $385 \mathrm{~nm}$ using a plate reader.

\subsection{Measurement of Lipolysis}

Lipolysis was evaluated by measuring the amount of glycerol and free fatty acids released into the media. In brief, lipolysis was evaluated by measuring the amount of glycerol and free fatty acids released to the media. Glycerol level was determined after $48 \mathrm{~h}$ of oligomycin and celastrol treatments while free fatty acids release were quantified after $3 \mathrm{~h}$ of drugs treatment by using the Lipolysis Assay Kit for Free Fatty Acids and Glycerol Detection (Zen-Bio Inc, Research Triangle Park, NC, USA) according to the manufacturer's instructions.

\subsection{Quantification of Lipid Contents by Oil Red O Assay}

Intracellular accumulations of lipid droplets were determined by oil red $\mathrm{O}$ staining. This assay was performed as previously mentioned [66]. Briefly, $0.7 \mathrm{~g}$ of oil red $\mathrm{O}$ was dissolved in $200 \mathrm{~mL}$ of isopropanol and filtered with $0.2 \mu \mathrm{m}$. The solution was diluted into a ratio of 6:4 with distilled water. The solution was then mixed and allowed to stand for $20 \mathrm{~min}$ at room temperature. The cells were washed with $10 \%$ formalin in PBS and stained with a filtered staining solution for $10 \mathrm{~min}$ at $37{ }^{\circ} \mathrm{C}$. The stained cells were washed again three times with distilled water and observed under inverted fluorescence microscope (Carl Zeiss, Göttingen, Germany) equipped with the digital camera AxioCam MRc (Carl Zeiss) for morphological study. For quantification of lipid content, the oil red $\mathrm{O}$ was eluted by adding 100\% isopropanol and incubated for $10 \mathrm{~min}$ before measuring the absorbance (OD) at $490 \mathrm{~nm}$ using ELISA plate reader.

\subsection{Cytokine ELISA for TNF- $\alpha$ and IL-1 $\beta$ Measurement}

The concentrations of pro-inflammatory cytokines TNF- $\alpha$ and IL-1 $\beta$ in the harvested medium from adipocytes were measured using a commercially available enzyme-linked immunosorbent assay (ELISA) kit (Invitrogen, Carlsbad, CA, USA) according to the manufacturer's protocol. The minimum detectable doses were $7 \mathrm{pg} / \mathrm{mL}$ for IL- $1 \beta$ and $3 \mathrm{pg} / \mathrm{mL}$ for TNF- $\alpha$. Each concentration was obtained from the standard curve and expressed as per mg of total extractable cell protein.

\subsection{Glucose Uptake Assay}

To evaluate increased dependence on glycolytic metabolism in the presence of mitochondrial inhibitors, glucose uptake activity was performed by quantifying the uptake of radio-labelled glucose. Briefly, the differentiated cells with and without treatment were grown in 12-well plates and washed twice with serum-free media and incubated for $3 \mathrm{~h}$ at $37^{\circ} \mathrm{C}$. The cells were washed three times with 
Krebs-Ringer HEPES (KRPH) buffer and undergo incubation with $0.9 \mathrm{~mL}$ of KRPH buffer for $30 \mathrm{~min}$ at $37^{\circ} \mathrm{C}$. The activity of glucose uptake was quantified by the addition of $0.1 \mathrm{~mL}$ of KRPH buffer comprising 2-deoxy-D- $\left[{ }^{3} \mathrm{H}\right]$ glucose $(0.037 \mathrm{MBq}$; Perkin Elmer, Foster City, CA, USA) and glucose $(0.001 \mathrm{mM})$. The glucose uptake activity was terminated right after $60 \mathrm{~min}$, through washing the cells three times with ice-cold PBS. The cells were lysed through incubation for 20 min at $37^{\circ} \mathrm{C}$ with $0.7 \mathrm{~mL}$ of $1 \%$ Triton X-100. The radioactivity level in the cell lysates were quantified by using Tri-Carb $2700 \mathrm{TR}$ liquid scintillation counter.

\subsection{Statistical Analysis}

Experimental results were shown as the mean means \pm standard error of the mean (SEM) of the indicated sample size $(n)$. Statistical significance of data was determined using paired and unpaired Student's $t$-test. One-way ANOVA with Tukey post-hoc was utilized where more than two groups were compared with treatments. A value of $p<0.05$ was considered as statistically significant.

\section{Conclusions}

In summary, based on the results obtained in this study, we have proposed additional support to the hypothesis that a decline in mitochondrial function is significantly associated with differentiated 3T3-L1 adipocytes inflammatory phenotype observed in insulin resistance-associated diseases. The results of the present study verify that mitochondrial dysfunction alone may disturb oxidative metabolism and promotes low-grade inflammation in adipocytes. These metabolic insults were ameliorated by the addition of celastrol on the differentiated adipocytes with mitochondrial dysfunction. To our best knowledge, this is the first report demonstrating deterioration of mitochondrial function in adipocytes with insulin resistance is correlated with the activation of NF- $\kappa \mathrm{B}$ pathways. The limitation of the present study is the use of in vitro model of 3T3-L1 adipocytes to observe such effects on the ameliorative properties of NF- $\kappa \mathrm{B}$ inhibitor. The use of different methodologies in further evaluating NF- $\mathrm{B}$ expression activity is imperatively needed. In addition, future analyses involving in vivo and human studies should be continued to explicate the role of this inflammatory signaling pathway in these metabolic perturbations. However, our results have substantiated the mechanistic role of inflammation in the dysregulation of oxidative metabolism in adipose tissues. The study have provided valuable information for the development of an envisaged therapeutic strategy in insulin resistance and type 2 diabetes.

\section{Acknowledgments}

The authors would like to thank the Ministry of Education, Malaysia under Fundamental Research Grant Scheme (FRGS-2013-2015) and Universiti Teknologi Malaysia (Vot. No. R.J130000.7809.4F284) for financial and technical supports. Mohamad Hafizi Abu Bakar is sponsored by "UTM Doctoral Zamalah Award" at Universiti Teknologi Malaysia. 


\section{Author Contributions}

Mohamad Hafizi Abu Bakar wrote the paper, designed and performed the experiments; Mohamad Roji Sarmidi, Cheng Kian Kai, Hasniza Zaman Huri and Harisun Yaakob revised the manuscript critically for important intellectual content. All authors read and approved the final manuscript.

\section{Conflicts of Interest}

All authors declare no conflict of interest.

\section{References}

1. Wei, Y.; Chen, K.; Whaley-Connell, A.T.; Stump, C.S.; Ibdah, J.A.; Sowers, J.R. Skeletal muscle insulin resistance: Role of inflammatory cytokines and reactive oxygen species. Am. J. Physiol. Regul. Integr. Comp. Physiol. 2008, 23, R673-R680.

2. Hafizi Abu Bakar, M.; Kian Kai, C.; Wan Hassan, W.N.; Sarmidi, M.R.; Yaakob, H.; Zaman Huri, H. Mitochondrial dysfunction as a central event for mechanisms underlying insulin resistance: The roles of long chain fatty acids. Diabetes Metab. Res. Rev. 2014, doi:org/10.1002/dmrr.2601.

3. Martins, A.R.; Nachbar, R.T.; Gorjao, R.; Vinolo, M.A; Festuccia, W.T.; Lambertucci, R.H.; Cury-Boaventura, M.F.; Silveira, L.R.; Curi, R.; Hirabara, S.M. Mechanisms underlying skeletal muscle insulin resistance induced by fatty acids: Importance of the mitochondrial function. Lipids Health Dis. 2012, 11, 30.

4. Fernández-Sánchez, A.; Madrigal-Santillán, E.; Bautista, M.; Esquivel-Soto, J.; Morales-González, A.; Esquivel-Chirino, C.; Durante-Montiel, I.; Sánchez-Rivera, G.; Valadez-Vega, C.; Morales-González, J.A. Inflammation, oxidative stress, and obesity. Int. J. Mol. Sci. 2011, 12, 3117-3132.

5. Hernández-Aguilera, A.; Rull, A.; Rodríguez-Gallego, E.; Riera-Borrull, M.; Luciano-Mateo, F.; Camps, J.; Menéndez, J.A.; Joven, J. Mitochondrial dysfunction: A basic mechanism in inflammation-related non-communicable diseases and therapeutic opportunities. Mediators Inflamm. 2013, doi:org/10.1155/2013/135698.

6. Bondia-Pons, I.; Ryan, L.; Martinez, J.A. Oxidative stress and inflammation interactions in human obesity. J. Physiol. Biochem. 2012, 68, 701-711.

7. Naik, E.; Dixit, V.M. Mitochondrial reactive oxygen species drive proinflammatory cytokine production. J. Exp. Med. 2011, 208 , 417-420.

8. Halberg, N.; Wernstedt-Asterholm, I.; Scherer, P.E. The adipocyte as an endocrine cell. Endocrinol. Metab. Clin. N. Am. 2008, 37, 753-768.

9. Cinti, S.; Mitchell, G.; Barbatelli, G.; Murano, I.; Ceresi, E.; Faloia, E.; Wang, S.; Fortier, M.; Greenberg, A.S.; Obin, M.S. Adipocyte death defines macrophage localization and function in adipose tissue of obese mice and humans. J. Lipid Res. 2005, 46, 2347-2355.

10. Trayhurn, P.; Wood, I.S. Adipokines: Inflammation and the pleiotropic role of white adipose tissue. Br. J. Nutr. 2004, 92, 347-355.

11. Gregor, M.F.; Hotamisligil, G.S. Inflammatory mechanisms in obesity. Annu. Rev. Immunol. 2011, $29,415-445$. 
12. Lee, B.C.; Lee, J. Cellular and molecular players in adipose tissue inflammation in the development of obesity-induced insulin resistance. Biochim. Biophys. Acta 2014, 1842, 446-462.

13. Weisberg, S.P.; McCann, D.; Desai, M.; Rosenbaum, M.; Leibel, R.L.; Ferrante, A.W. Obesity is associated with macrophage accumulation in adipose tissue. J. Clin. Investig. 2003, 112, 1796-1808.

14. Cildir, G.; Akıncılar, S.C.; Tergaonkar, V. Chronic adipose tissue inflammation: All immune cells on the stage. Trends Mol. Med. 2013, 19, 487-500.

15. Chen, X.H.; Zhao, Y.P.; Xue, M.; Ji, C.B.; Gao, C.L.; Zhu, J.G.; Qin, D.N.; Kou, C.Z.; Qin, X.H.; Tong, M.L.; et al. TNF- $\alpha$ induces mitochondrial dysfunction in 3T3-L1 adipocytes. Mol. Cell Endocrinol. 2010, 328, 63-69.

16. Gao, C.L.; Zhu, C.; Zhao, Y.P.; Chen, X.H.; Ji, C.B.; Zhang, C.M.; Zhu, J.G.; Xia, Z.K.; Tong, M.L.; Guo, X.R. Mitochondrial dysfunction is induced by high levels of glucose and free fatty acids in 3T3-L1 adipocytes. Mol. Cell Endocrinol. 2010, 320, 25-33.

17. Youssef-Elabd, E.M.; McGee, K.C.; Tripathi, G.; Aldaghri, N.; Abdalla, M.S.; Sharada, H.M.; Ash, E.; Amin, A.I.; Ceriello, A.; O'Hare, J.P.; et al. Acute and chronic saturated fatty acid treatment as a key instigator of the TLR-mediated inflammatory response in human adipose tissue, in vitro. J. Nutr. Biochem. 2012, 23, 39-50.

18. Reynolds, C.M.; McGillicuddy, F.C.; Harford, K.A.; Finucane, O.M.; Mills, K.H.G.; Roche, H.M. Dietary saturated fatty acids prime the NLRP3 inflammasome via TLR4 in dendritic cells_-Implications for diet-induced insulin resistance. Mol. Nutr. Food Res. 2012, 56, 1212-1222.

19. Escames, G.; López, L.; García, J.; García-Corzo, L.; Ortiz, F.; Acuña-Castroviejo, D. Mitochondrial DNA and inflammatory diseases. Hum. Genet. 2012, 131, 161-173.

20. López-Armada, M.J.; Riveiro-Naveira, R.R.; Vaamonde-García, C.; Valcárcel-Ares, M.N. Mitochondrial dysfunction and the inflammatory response. Mitochondrion 2013, 13, 106-118.

21. Patel, S.; Santani, D. Role of NF-kB in the pathogenesis of diabetes and its associated complications. Pharmacol. Rep. 2009, 61, 595-603.

22. Vaamonde-García, C.; Riveiro-Naveira, R.R.; Valcárcel-Ares, M.N.; Hermida-Carballo, L.; Blanco, F.J.; López-Armada, M.J. Mitochondrial dysfunction increases inflammatory responsiveness to cytokines in normal human chondrocytes. Arthritis Rheumatol. 2012, 64, 2927-2936.

23. Yang, H.; Chen, D.; Cui, Q.C.; Yuan, X.; Dou, Q.P. Celastrol, a triterpene extracted from the Chinese "Thunder of God Vine", is a potent proteasome inhibitor and suppresses human prostate cancer growth in nude mice. Cancer Res. 2006, 66 , 4758-4765.

24. Allison, A.C.; Cacabelos, R.; Lombardi, V.R.M.; Álvarez, X.A.; Vigo, C. Celastrol, a potent antioxidant and anti-inflammatory drug, as a possible treatment for Alzheimer's disease. Prog. Neuro-Psychoph. Biol. Psychiatry 2001, 25, 1341-1357.

25. Lee, J.H.; Koo, T.H.; Yoon, H.; Jung, H.S.; Jin, H.Z.; Lee, K.; Hong, Y.S.; Lee, J.J. Inhibition of $\mathrm{NF}-\kappa \mathrm{B}$ activation through targeting I $\mathrm{B}$ kinase by celastrol, a quinone methide triterpenoid. Biochem. Pharmacol. 2006, 72, 1311-1321.

26. Kim, J.E.; Lee, M.H.; Nam, D.H.; Song, H.K.; Kang, Y.S.; Lee, J.E.; Kim, H.W.; Cha, J.J.; Hyun, Y.Y.; Han, S.Y.; et al. Celastrol, an NF- $\kappa \mathrm{B}$ inhibitor, improves insulin resistance and attenuates renal injury in $d b / d b$ mice. PLoS One 2013, 8, e62068.

27. Frohnert, B.I.; Bernlohr, D.A. Protein carbonylation, mitochondrial dysfunction, and insulin resistance. Adv. Nutr. 2013, 4, 157-163. 
28. Suzawa, M.; Takada, I.; Yanagisawa, J.; Ohtake, F.; Ogawa, S.; Yamauchi, T.; Kadowaki, T.; Takeuchi, Y.; Shibuya, H.; Gotoh, Y.; et al. Cytokines suppress adipogenesis and PPAR $\gamma$ function through the TAK1/TAB1/NIK cascade. Nat. Cell Biol. 2003, 5, 224-230.

29. Ruan, H.; Hacohen, N.; Golub, T.R.; van Parijs, L.; Lodish, H.F. Tumor necrosis factor- $\alpha$ suppresses adipocyte-specific genes and activates expression of preadipocyte genes in 3T3-L1 adipocytes: Nuclear factor- $\kappa \mathrm{B}$ activation by TNF- $\alpha$ is obligatory. Diabetes 2002, 51, 1319-1336.

30. Wang, C.H.; Wang, C.C.; Wei, Y.H. Mitochondrial dysfunction in insulin insensitivity: Implication of mitochondrial role in type 2 diabetes. Ann. N. Y. Acad. Sci. 2010, 1201, 157-165.

31. Wang, C.H.; Wang, C.C.; Huang, H.C.; Wei, Y.H. Mitochondrial dysfunction leads to impairment of insulin sensitivity and adiponectin secretion in adipocytes. FEBS J. 2013, 280, 1039-1050.

32. Choo, H.J.; Kim, J.H.; Kwon, O.B.; Lee, C.; Mun, J.; Han, S.; Yoon, Y.S.; Yoon, G.; Choi, K.M.; Ko, Y.G. Mitochondria are impaired in the adipocytes of type 2 diabetic mice. Diabetologia 2006, 49, 784-791.

33. Kusminski, C.M.; Scherer, P.E. Mitochondrial dysfunction in white adipose tissue. Trends Endocrinol. Metab. 2012, 23, 435-443.

34. Vaamonde-García, C.; Valcarcel-Ares, N.; Riveiro-Naveira, R.; Lema, B.; Blanco, F.J.; López-Armada, M.J. Inflammatory response is modulated by mitochondrial dysfunction in cultured normal human chondrocytes. Ann. Rheum. Dis. 2010, 69, A15-A16.

35. Bulua, A.C.; Simon, A.; Maddipati, R.; Pelletier, M.; Park, H.; Kim, K.Y.; Sack, M.N.; Kastner, D.L.; Siegel, R.M. Mitochondrial reactive oxygen species promote production of proinflammatory cytokines and are elevated in TNFR1-associated periodic syndrome (TRAPS). J. Exp. Med. 2011, 208, 519-533.

36. Ungvari, Z.; Orosz, Z.; Labinskyy, N.; Rivera, A.; Zhao, X.M.; Smith, K.; Csiszar, A. Increased mitochondrial $\mathrm{H}_{2} \mathrm{O}_{2}$ production promotes endothelial $\mathrm{NF}-\kappa \mathrm{B}$ activation in aged rat arteries. Am. J. Physiol. Heart Circ. Physiol. 2007, 293, H37-H47.

37. Ishihara, N.; Eura, Y.; Mihara, K. Mitofusin 1 and 2 play distinct roles in mitochondrial fusion reactions via GTPase activity. J. Cell Sci. 2004, 117, 6535-6546.

38. Suen, D.F.; Norris, K.L.; Youle, R.J. Mitochondrial dynamics and apoptosis. Genes Dev. 2008, 22, $1577-1590$.

39. Zemirli, N.; Pourcelot, M.; Ambroise, G.; Hatchi, E.; Vazquez, A.; Arnoult, D. Mitochondrial hyperfusion promotes NF- $\mathrm{BB}$ activation via the mitochondrial E3 ligase MULAN. FEBS J. 2014, 281, 3095-3112.

40. Mariappan, N.; Elks, C.M.; Sriramula, S.; Guggilam, A.; Liu, Z.; Borkhsenious, O.; Francis, J. NF- $\mathrm{kB}$-induced oxidative stress contributes to mitochondrial and cardiac dysfunction in type II diabetes. Cardiovasc. Res. 2010, 85 , 473-483.

41. Salminen, A.; Kaarniranta, K.; Kauppinen, A. Inflammaging: Disturbed interplay between autophagy and inflammasomes. Aging (Albany NY) 2012, 4, 166-175.

42. Lee, H.K.; Song, J.H.; Shin, C.S.; Park, D.J.; Park, K.S.; Lee, K.U.; Koh, C.S. Decreased mitochondrial DNA content in peripheral blood precedes the development of non-insulin-dependent diabetes mellitus. Diabetes Res. Clin. Pract. 1998, 42, 161-167. 
43. Morino, K.; Petersen, K.F.; Dufour, S.; Befroy, D.; Frattini, J.; Shatzkes, N.; Neschen, S.; White, M.F.; Bilz, S.; Sono, S.; et al. Reduced mitochondrial density and increased IRS-1 serine phosphorylation in muscle of insulin-resistant offspring of type 2 diabetic parents. J. Clin. Investig. 2005, 115, 3587-3593.

44. Stienstra, R.; Joosten, L.A.B.; Koenen, T.; van Tits, B.; van Diepen, J.A.; van den Berg, S.A.A.; Rensen, P.C.N.; Voshol, P.J.; Fantuzzi, G.; Hijmans, A.; et al. The inflammasome-mediated caspase-1 activation controls adipocyte differentiation and insulin sensitivity. Cell Metab. 2010, 12, 593-605.

45. Morita, M.; Yano, S.; Yamaguchi, T.; Sugimoto, T. Advanced glycation end products-induced reactive oxygen species generation is partly through $\mathrm{NF}-\kappa \mathrm{B}$ activation in human aortic endothelial cells. J. Diabetes Complicat. 2013, 27, 11-15.

46. Curtis, J.M.; Hahn, W.S.; Stone, M.D.; Inda, J.J.; Droullard, D.J.; Kuzmicic, J.P.; Donoghue, M.A.; Long, E.K.; Armien, A.G.; Lavandero, S.; et al. Protein carbonylation and adipocyte mitochondrial function. J. Biol. Chem. 2012, 287, 32967-32980.

47. Frohnert, B.I.; Sinaiko, A.R.; Serrot, F.J.; Foncea, R.E.; Moran, A.; Ikramuddin, S.; Choudry, U.; Bernlohr, D.A. Increased adipose protein carbonylation in human obesity. Obesity 2011, 19, 1735-1741.

48. Curtis, J.M.; Grimsrud, P.A.; Wright, W.S.; Xu, X.; Foncea, R.E.; Graham, D.W.; Brestoff, J.R.; Wiczer, B.M.; Ilkayeva, O.; Cianflone, K.; et al. Downregulation of adipose glutathione $S$-transferase A4 leads to increased protein carbonylation, oxidative stress, and mitochondrial dysfunction. Diabetes 2010, 59, 1132-1142.

49. Fang, J.; Holmgren, A. Inhibition of thioredoxin and thioredoxin reductase by 4-Hydroxy-2-nonenal in vitro and in vivo. J. Am. Chem. Soc. 2006, 128, 1879-1885.

50. Yadav, U.C.S.; Ramana, K.V. Regulation of NF- $\kappa B$-induced inflammatory signaling by lipid peroxidation-derived aldehydes. Oxid. Med. Cell Longev. 2013, doi:org/10.1155/2013/690545.

51. Altavilla, D.; Famulari, C.; Passaniti, M.; Campo, G.M.; MacrÌ, A.; Seminara, P.; Marini, H.; Calò, M.; Santamaria, L.B.; Bono, D.; et al. Lipid peroxidation inhibition reduces NF- $\kappa \mathrm{B}$ activation and attenuates cerulein-induced pancreatitis. Free Radic. Res. 2003, 37, 425-435.

52. Ji, C.; Chen, X.; Gao, C.; Jiao, L.; Wang, J.; Xu, G.; Fu, H.; Guo, X.; Zhao, Y. IL-6 induces lipolysis and mitochondrial dysfunction, but does not affect insulin-mediated glucose transport in 3T3-L1 adipocytes. J. Bioenerg. Biomembr. 2011, 43, 367-375.

53. Souza, S.C.; Palmer, H.J.; Kang, Y.H.; Yamamoto, M.T.; Muliro, K.V; Paulson, K.E.; Greenberg, A.S. TNF- $\alpha$ induction of lipolysis is mediated through activation of the extracellular signal related kinase pathway in 3T3-L1 adipocytes. J. Cell Biochem. 2003, 89, 1077-1086.

54. Laurencikiene, J.; van Harmelen, V.; Arvidsson Nordström, E.; Dicker, A.; Blomqvist, L.; Näslund, E.; Langin, D.; Arner, P.; Rydén, M. NF- $\kappa \mathrm{B}$ is important for TNF- $\alpha$-induced lipolysis in human adipocytes. J. Lipid Res. 2007, 48, 1069-1077.

55. Zuany-Amorim, C.; Hastewell, J.; Walker, C. Toll-like receptors as potential therapeutic targets for multiple diseases. Nat. Rev. Drug Discov. 2002, 1, 797-807.

56. Xie, L.; Ortega, M.T.; Mora, S.; Chapes, S.K. Interactive changes between macrophages and adipocytes. Clin. Vaccine Immunol. 2010, 17, 651-659. 
57. Li, N.; Karin, M. Is NF-кB the sensor of oxidative stress? FASEB J. 1999, 13, 1137-1143.

58. Emanuela, F.; Grazia, M.; de Marco, R.; Paola, L.M.; Giorgio, F.; Marco, B. Inflammation as a link between obesity and metabolic syndrome. J. Nutr. Metab. 2012, doi:org/10.1155/2012/476380.

59. Mauro, C.; Leow, S.C.; Anso, E.; Rocha, S.; Thotakura, A.K.; Tornatore, L.; Moretti, M.; de Smaele, E.; Beg, A.A.; Tergaonkar, V.; et al. NF-кB controls energy homeostasis and metabolic adaptation by upregulating mitochondrial respiration. Nat. Cell Biol. 2011, 13, 1272-1279.

60. Bogan, J.S. Regulation of glucose transporter translocation in health and diabetes. Annu. Rev. Biochem. 2012, 81, 507-532.

61. Nandi, A.;. Kitamura, Y.; Kahn, C.R.; Accili, D. Mouse models of insulin resistance. Physiol. Rev. 2004, 84, 623-647.

62. Wei, B.; Ta, N.; Li, J.; Zhang, J.; Chen, B. Relationship between the inhibition of NF- $\kappa$ B and insulin resistance in uterrus of rats with gestational diabetes mellitus. Chin. J. Cell Mol. Immunol. 2010, 26, 235-237, 241.

63. Wu, N.; Zheng, B.; Shaywitz, A.; Dagon, Y.; Tower, C.; Bellinger, G.; Shen, C.H.; Wen, J.; Asara, J.; McGraw, T.E.; et al. AMPK-dependent degradation of TXNIP upon energy stress leads to enhanced glucose uptake via GLUT1. Mol. Cell 2013, 49, 1167-1175.

64. Schubert, D. Glucose metabolism and Alzheimer's disease. Ageing Res. Rev. 2005, 4, $240-257$.

65. Kussmann, M.; Morine, M.; Hager, J.; Sonderegger, B.; Kaput, J. Perspective: A system approach to diabetes research. Front. Genet. 2013, 4, 205.

66. Miki, H.; Yamauchi, T.; Suzuki, R.; Komeda, K.; Tsuchida, A.; Kubota, N.; Terauchi, Y.; Kamon, J.; Kaburagi, Y.; Matsui, J.; et al. Essential role of insulin receptor substrate 1 (IRS-1) and IRS-2 in adipocyte differentiation. Mol. Cell. Biol. 2001, 21, 2521-2532.

67. Hossner, K.L. Hormonal Regulation of Farm Animal Growth; CABI: Cambrige, MA, USA, 2005; p. 174.

68. Huang, C.; Zhang, Y.; Gong, Z.; Sheng, X.; Li, Z.; Zhang, W.; Qin, Y. Berberine inhibits 3T3-L1 adipocyte differentiation through the PPAR $\gamma$ pathway. Biochem. Biophys. Res. Commun. 2006, 348 , 571-578.

69. Singh, B.; Bhat, H.K. Superoxide dismutase 3 is induced by antioxidants, inhibits oxidative DNA damage and is associated with inhibition of estrogen-induced breast cancer. Carcinogenesis 2012, $33,2601-2610$.

(C) 2014 by the authors; licensee MDPI, Basel, Switzerland. This article is an open access article distributed under the terms and conditions of the Creative Commons Attribution license (http://creativecommons.org/licenses/by/4.0/). 